\title{
Seismic Performance Evaluation of Footing-to-Circular RC Pier Connection Reinforced by High-Manganese Steel Bars (HMSBs)
}

\author{
Jung-Kyun Kim, ${ }^{1}$ Hak-Eun Lee $\mathbb{C D}^{1}{ }^{1}$ Jongmin Kim, ${ }^{2}$ and Jiho Moon $\mathbb{D D}^{3}$ \\ ${ }^{1}$ Department of Architectural, Civil \& Environmental Engineering, Korea University, Seoul 02841, Republic of Korea \\ ${ }^{2}$ Department of Steel Solution Marketing, POSCO, Incheon 21985, Republic of Korea \\ ${ }^{3}$ Department of Civil Engineering, Kangwon National University, Chuncheon-si, Gangwon-do 24341, Republic of Korea
}

Correspondence should be addressed to Jiho Moon; jmoon1979@gmail.com

Received 1 May 2018; Revised 8 August 2018; Accepted 6 September 2018; Published 4 October 2018

Academic Editor: Chiara Bedon

Copyright (@ 2018 Jung-Kyun Kim et al. This is an open access article distributed under the Creative Commons Attribution License, which permits unrestricted use, distribution, and reproduction in any medium, provided the original work is properly cited.

\begin{abstract}
A footing-to-reinforced concrete (RC) pier connection resists the lateral load induced by earthquakes as well as the gravity load. The footing-to-RC pier connection is the vulnerable part to strong earthquake loading. Several studies have been conducted on improving the seismic performance of the connection by using high-strength reinforcing bars and by adding special structural components, such as steel tube and fiber-reinforced polymer sheet. In this study, reinforcing bars made of high-manganese steel (HMSBs) with high strength and ductility were installed in the connection instead of conventional reinforcing bars to improve the seismic performance. Test specimens were fabricated with HMSBs, and the strength, ductility, and dissipated energy of the connection were evaluated through a cyclic loading test. Three-dimensional finite-element analysis was also performed to investigate the effects of various axial forces on the behavior of the connection with HMSBs. The results show that the connection with HMSBs exhibits better seismic performance, represented by flexural strength, ductility, and energy dissipation, than that with ordinary reinforcing bars.
\end{abstract}

\section{Introduction}

The substructure of a bridge generally consists of a coping, pier, and footing. In a reinforced-concrete pier (RC pier), reinforcement steel inside the pier extends into the coping or footing to connect each component. The substructure of the bridge resists the gravity load as well as lateral loads induced by events such as earthquakes. The connection between the footing and pier is the most vulnerable part to earthquake loading. Thus, to improve the seismic performance, it is necessary to reinforce the footing-to-RC pier connection.

Several studies have been conducted for this purpose by using high-strength reinforcing bars [1-4] or fiberreinforced concrete $[5,6]$. Ou et al. [1] studied the cyclic behavior of precast segmental concrete bridge columns with high-performance or conventional steel reinforcing bars as energy dissipation bars. Xiao et al. [2] evaluated the seismic performance of rectangular high-strength concrete frame columns with ultrahigh-strength bars. From their results, the use of high-strength reinforcing bars increased both strength and ductility. Additionally, Su et al. [3] investigated the effect of the reinforcing bar yield strength on the strength and ductility of the pier connection, and Budek et al. [4] studied the flexural behavior of columns with high-strength wire and strand as transverse reinforcement. These studies [1-4] focused on the use of high-strength reinforcing bars to improve the seismic performance of the RC column connection. Deng and Zhang [5] evaluated seismic performance of short concrete columns with high-ductility fiber-reinforced concrete under lateral cyclic loading. Their results showed that the drift ratio and energy dissipation increased when ordinary RC was changed to highductility fiber-reinforced concrete in short concrete columns. Lepage et al. [6] investigated the deformation capacity and flexural strength of seismic-resistant frames with highperformance steel bars and fibers. The evidence presented in their study showed that the use of advanced high-strength steel as longitudinal reinforcement in frame members is a viable option for seismic-resistant construction. 
The effect of the deformation capacity (ductility) of the reinforcing bar is an important parameter that affects the seismic performance of RC pier connections. Recently, a new high-manganese steel (HMS) was developed by POSCO, a steel company from the Republic of Korea. This steel has excellent deformation capacity, such that its energy dissipation ability is much greater than that of ordinary conventional steel. The percentage of manganese in HMSs is approximately $18-22 \%$, whereas that of ordinary steel is under $0.6-1.6 \%$. According to Sasaki et al. [7], when the carbon content is constant, the strength, elongation, and toughness increase with manganese content in the range of 10-25\%. Generally, HMSs show a high ductility in tensile performance evaluations. Figure 1 shows the stress-strain relationship of the conventional steel generally used in reinforcing bar and the HMS used in this study. It can be seen that HMS has a higher yield stress and higher ultimate tensile stress than conventional steel, as well as a high ultimate tensile strain at failure. Thus, by using this HMS for reinforcing bars, one might improve the seismic performance of the RC pier connection, in terms of both strength and ductility.

In this study, a high-manganese steel bar (HMSB) was fabricated and installed in the connection between the footing and circular RC pier to investigate the seismic performance of the footing-to-circular RC pier connection. A series of tests were conducted, and the strength and ductility were evaluated for the connection with HMSBs. Furthermore, three-dimensional (3D) finite-element analysis (FEA) was performed for in-depth analysis of the behavior of the proposed connection and to investigate the effect of the axial load on the connection behavior. The results showed that the connection reinforced by HMSBs had excellent seismic performance compared to that of ordinary RC connections.

\section{Test}

2.1. Description of the Test Specimen. In this study, two different test specimens were constructed to investigate the effect of HMSB on the seismic performance of a circular RC connection to the footing. The reference specimen, named "T-SD400," contains longitudinal reinforcing bars of crosssectional area $132.73 \mathrm{~mm}^{2}$ (diameter $13 \mathrm{~mm}$ ), made of SD400-D13, which has a nominal yield strength of $400 \mathrm{MPa}$. The T-HMSB specimen has the same dimensions as T-SD400. However, the longitudinal SD400-D13 reinforcing bars were replaced by HMSBs, which have almost the same cross-sectional area $\left(132 \mathrm{~mm}^{2}\right)$, as shown in Figure 2.

Because commercial reinforcing bars made of HMS have not been produced yet, the HMSBs were specially fabricated by cutting an HMS plate, as shown in Figures 3(a) and 3(b). The HMS plate (thickness $=12 \mathrm{~mm}$ ) was cut by a water jet of width $11 \mathrm{~mm}$. The HMSB has a rectangular cross section and no ribs on its surface. Then, the HMSBs were placed as longitudinal reinforcing bars in the T-HMSB specimen, as shown in Figure 3(c). Figure 3(d) shows the reinforcing bar assembly for the reference specimen.

The layout of the test specimens and the arrangement of the reinforcing bars are shown in Figures 4(a) and 4(b),

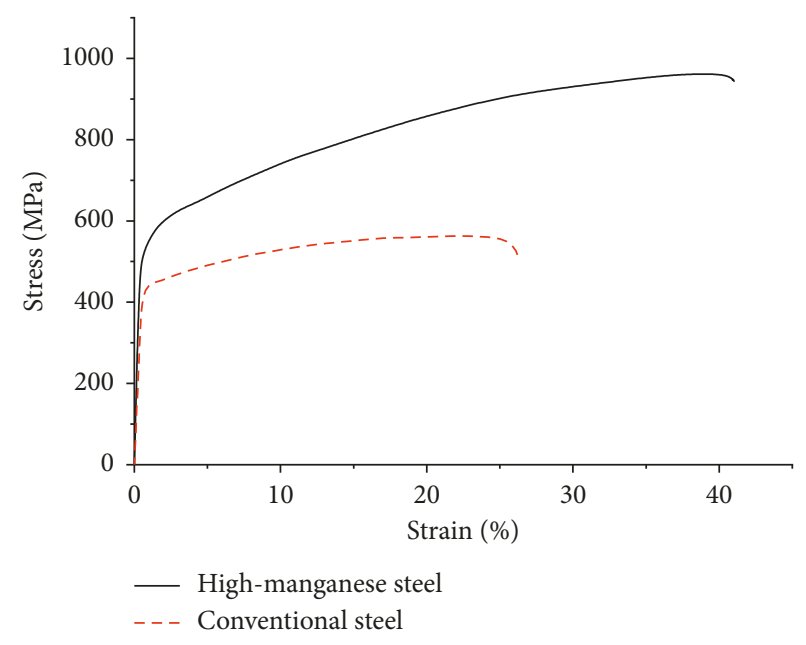

FIgURE 1: The stress-strain curve of reinforcing steels.

respectively. Detailed dimensions of the specimens are listed in Table 1. The total height of the specimen was $3,000 \mathrm{~mm}$, and the height of the footing $\left(L_{\mathrm{f}}\right)$ was $800 \mathrm{~mm}$. The footing was rectangular, with a width $\left(W_{\mathrm{f}}\right)$ of $2,470 \mathrm{~mm}$ and depth $\left(B_{\mathrm{f}}\right)$ of $1,000 \mathrm{~mm}$. The distance from the bottom of the pier to the center of the loading point $\left(L_{\mathrm{p}}\right)$ was set as $2,200 \mathrm{~mm}$, and the diameter of the pier $\left(D_{\mathrm{p}}\right)$ was $512 \mathrm{~mm}$. Thus, the length-to-diameter ratio was 4.3. In Table $1, A_{\mathrm{c}}$ and $A_{\mathrm{s}}$ are the cross-sectional area of the circular concrete pier and total area of the reinforcing bars, respectively.

Sixteen SD400-D13 bars and HMSBs were installed for the T-SD400 and T-HMSB specimens. The reinforcement ratios in the longitudinal direction $\left(\rho_{\mathrm{b}, \mathrm{l}}\right)$ were $1.031 \%$ and $1.026 \%$, respectively, which satisfy the requirements for longitudinal reinforcements of the AASHTO LRFD design code [8].

The SD400-D10 bars, which were $10 \mathrm{~mm}$ in diameter and had nominal yield strength of $400 \mathrm{MPa}$, were used as transverse spiral reinforcing bars for both test specimens and placed at $70 \mathrm{~mm}$ intervals near the connection and at $140 \mathrm{~mm}$ intervals elsewhere. The AASHTO LRFD design code [8] indicates that transverse reinforcement for confinement in the plastic hinge region shall satisfy either

$$
\rho_{\mathrm{b}, \mathrm{t}} \geq 0.45\left(\frac{A_{\mathrm{c}}}{A_{\mathrm{co}}}-1\right) \frac{f_{\mathrm{c}}^{\prime}}{f_{\mathrm{y}}}
$$

or

$$
\rho_{\mathrm{b}, \mathrm{t}} \geq 0.12 \frac{f_{\mathrm{c}}^{\prime}}{f_{\mathrm{y}}},
$$

where $A_{\text {co }}$ is the area of the core confined with spiral reinforcement, $f_{\mathrm{c}}^{\prime}$ is the specified compressive strength (MPa) of the concrete at 28 days, and $f_{\mathrm{y}}$ is the yield strength of the reinforcing bar. These values were $0.81 \%$ and $0.95 \%$, respectively, and the ratio of spiral reinforcement to total volume of concrete core $\left(\rho_{\mathrm{b}, \mathrm{t}}\right)$ in the connection zone (see Figure 4(b)) was $0.98 \%$, which satisfies these specifications.

According to the AASHTO LRFD design code [8], the basic development length, $l_{\mathrm{hb}}$, for a hooked deformed bar in 


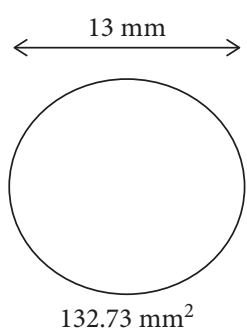

(a)

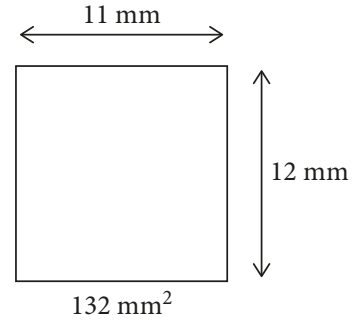

(b)

FIgURE 2: Cross section of reinforcing bars: (a) SD400 bar and (b) HMSB.

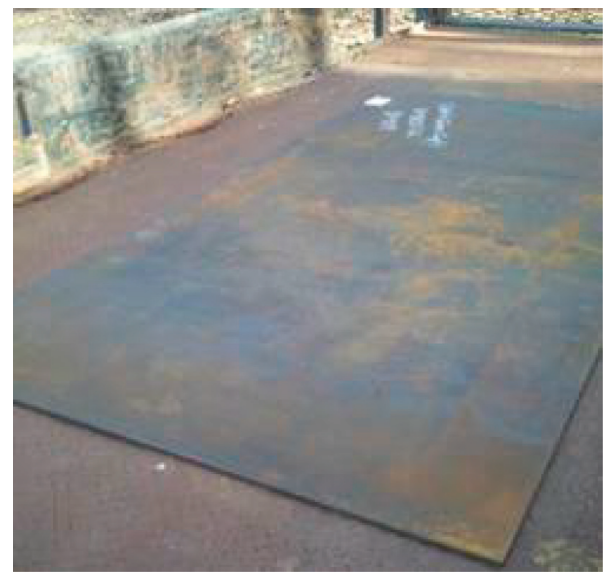

(a)

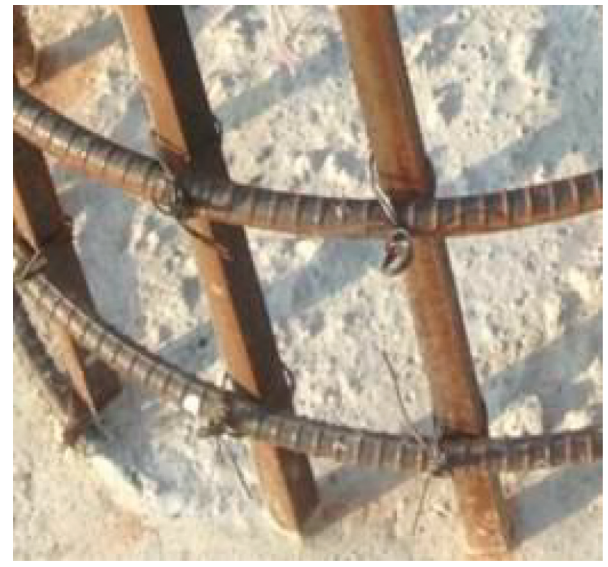

(c)

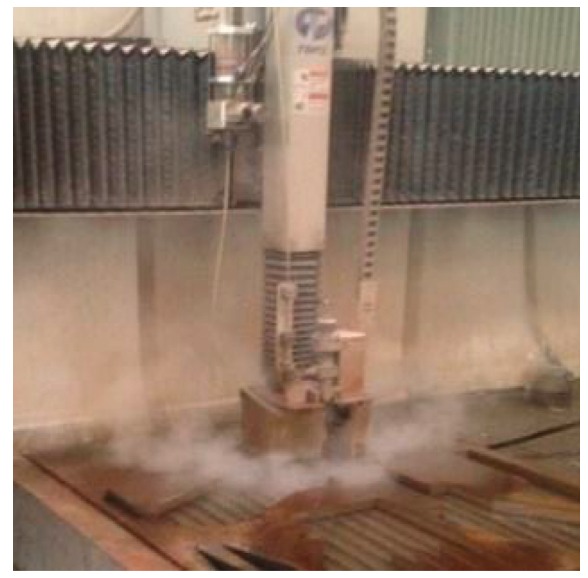

(b)

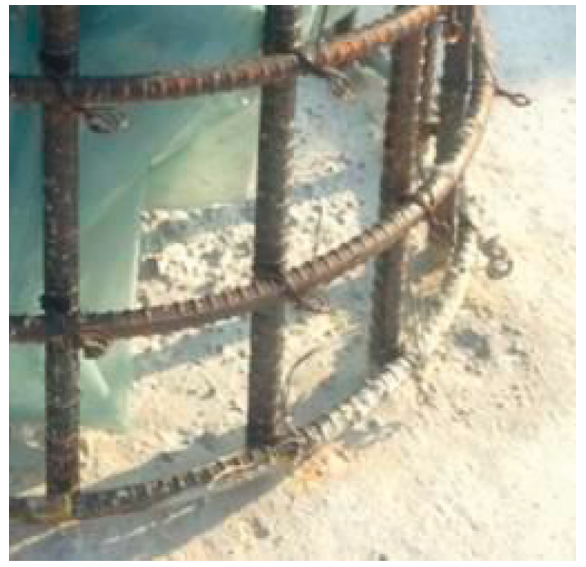

(d)

FIgURe 3: The process of fabricating HMSBs and rebar assembly for an RC pier connection: (a) HMS plate; (b) water-jet cutting; (c) rebar assembly (T-HMSB); and (d) rebar assembly (T-SD400).

tension with yield strength, $f_{\mathrm{y}}$, not exceeding $420 \mathrm{MPa}$ shall be taken as

$$
l_{\mathrm{hb}}=\frac{100 d_{\mathrm{b}}}{\sqrt{f_{\mathrm{c}}^{\prime}}},
$$

where $d_{\mathrm{b}}$ is the diameter ( $\mathrm{mm}$ ) of the reinforcement bar. In the case of T-SD400, the calculated basic development length was $220 \mathrm{~mm}$. In the case of T-HMSB, because the yield strength of HMSB exceeds $420 \mathrm{MPa}$, the basic development length of T-HMSB should be multiplied by an increasing factor $\left(f_{\mathrm{y}} / 420=1.3\right)$. In addition, according to the historical ACI code (1963), the basic development length for plain bar should be double that for deformed bar under similar conditions, as discussed by Poudyal [9]. As a result, the basic development length of T-HMSB was calculated as $566 \mathrm{~mm}$. In the test, to exert a sufficient embedment force, the development lengths of both T-SD400 and T-HMSB were $760 \mathrm{~mm}$, as shown in Figure 4(b).

Material tests were conducted for the reinforcing bars and concrete. From the results, the yield stress of an SD400 bar and HMSB was $440 \mathrm{MPa}$ and $540 \mathrm{MPa}$, respectively. The 


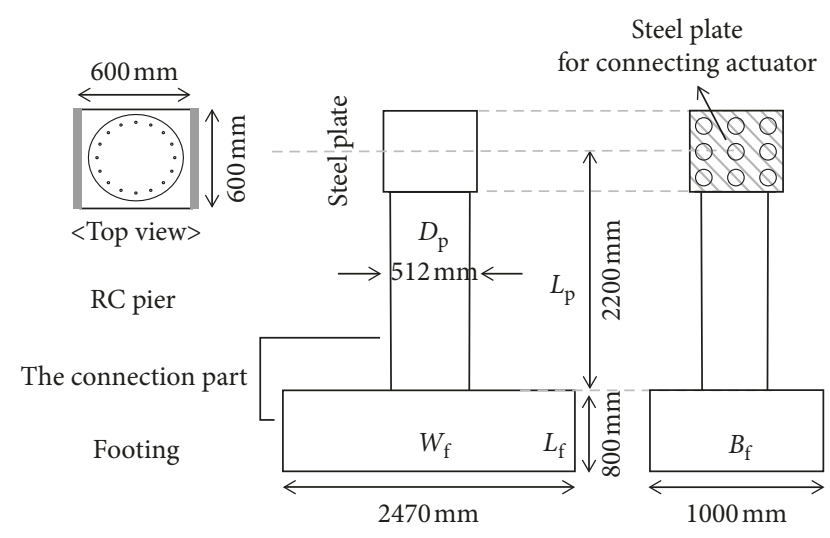

(a)

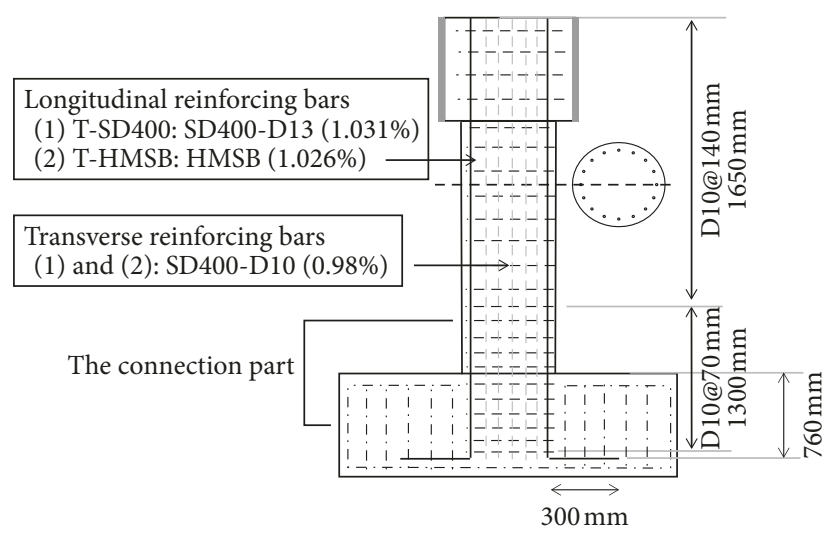

(b)

Figure 4: Test specimen layout: (a) dimensions and (b) reinforcement arrangement.

Table 1: Dimensions of test specimens.

\begin{tabular}{lccccccccc}
\hline Specimen & $D_{\mathrm{p}}(\mathrm{mm})$ & $L_{\mathrm{p}}(\mathrm{mm})$ & $L_{\mathrm{f}}(\mathrm{mm})$ & $W_{\mathrm{f}}(\mathrm{mm})$ & $B_{\mathrm{f}}(\mathrm{mm})$ & $A_{\mathrm{c}}\left(\mathrm{mm}^{2}\right)$ & $A_{\mathrm{s}}\left(\mathrm{mm}^{2}\right)$ & $\rho_{b, l}(\%)$ & $\rho_{b, t}(\%)$ \\
\hline T-SD400 & 512 & 2,200 & 800 & 2,470 & 1,000 & 205,887 & 2123.72 & 1.031 & 0.23 \\
T-HMSB & 512 & 2,200 & 800 & 2,470 & 1,000 & 205,887 & 2112 & 1.026 & 0.23 \\
\hline
\end{tabular}

ultimate tensile stress of an SD400 bar and HMSB was $550 \mathrm{MPa}$ and $945 \mathrm{MPa}$, respectively. The compressive strength of the concrete was $35 \mathrm{MPa}$.

It should be noted that the circular pier and the HMSB with rectangular section and plain surface are used in this study. Thus, the results in this study should be limited for these conditions.

Given the dimensions shown in Table 1 and the material test results, the theoretical strength of the cross section was evaluated by the strain compatibility method, as in elsewhere $[10,11]$. Figure 5 shows the strain and stress distribution of the cross section of the circular RC pier. In Figure 5, the diameter of the section is $h$, the distance between neutral axis and the top on the compressive side is $c$, and the depth of the equivalent rectangular stress block shaded grey is $a$. The distances from the top on the compressive side to the center of the tensile reinforcement and compressive reinforcement are designated as $d_{\mathrm{n}}$ and $d_{\mathrm{n}}^{\prime}$, respectively. The coefficient $\alpha$ is taken as 0.85 and $\beta$ is taken as 0.4 for $f_{c}^{\prime}=35 \mathrm{MPa}$. The coefficient $\beta_{1}=2 \beta$ is 0.8 and $\gamma=\alpha / \beta_{1}$ is 0.85 for $f_{\mathrm{c}}^{\prime}=35 \mathrm{MPa}$.

As shown in Figure 5, the axial force $\left(P_{\mathrm{n}}\right)$ and moment $\left(M_{\mathrm{n}}\right)$ can be obtained as

$$
\begin{aligned}
P_{\mathrm{n}} & =C_{\mathrm{c}}+\sum c_{\mathrm{sn}}-\sum t_{\mathrm{sn}}, \\
M_{\mathrm{n}} & =C_{\mathrm{c}}\left(\frac{h}{2}-\frac{a}{2}\right)+\sum c_{\mathrm{sn}}\left(\frac{h}{2}-d_{\mathrm{n}}^{\prime}\right)+\sum t_{\mathrm{sn}}\left(d_{\mathrm{n}}-\frac{h}{2}\right) \\
C_{\mathrm{c}} & =\gamma f_{\mathrm{c}}^{\prime} \beta_{1} A_{\mathrm{c}}^{\prime}, \\
c_{\mathrm{sn}} & =\frac{N A_{\mathrm{r}} f_{\mathrm{y}} \varepsilon_{\mathrm{sc}}}{\varepsilon_{y}}
\end{aligned}
$$

$$
t_{\mathrm{sn}}=\frac{N A_{\mathrm{r}} f_{\mathrm{y}} \varepsilon_{\mathrm{st}}}{\varepsilon_{y}}
$$

where $C_{\mathrm{c}}$ is the compression force of the concrete and $c_{\mathrm{sn}}$ and $t_{\mathrm{sn}}$ are the compression and tension forces of the reinforcing bars, respectively, based on the AISC [12]. $A_{\mathrm{r}}$ is the area of each reinforcement. $N$ is the number of reinforcements at the same $d_{\mathrm{n}}$ or $d_{\mathrm{n}}^{\prime}$ in Figure 5. $N$ is 1 for $c_{\mathrm{s} 1}$ and $t_{\mathrm{s} 1}$ and $N$ is 2 for the others. $\varepsilon_{\mathrm{sc}}$ and $\varepsilon_{\mathrm{st}}$ are the compressive and the tensile strain of the reinforcements, respectively.

From the calculation results, $P-M$ interaction curves are constructed as shown in Figure 6. For zero axial force, the theoretical ultimate bending moments $\left(M_{\mathrm{u}, \mathrm{SCM}}\right)$ of the T-SD400 and T-HMSB specimens are $214.2 \mathrm{kN} \cdot \mathrm{m}$ and $271.7 \mathrm{kN} \cdot \mathrm{m}$, respectively. These values are used to compare with the test results in later sections. In Figure 6, the balanced point of T-HMSB is located to the left from that of T-SD400. This is because the T-HMSB specimen has a higher relative strength ratio, $c_{\mathrm{sr}}=A_{\mathrm{S}} f_{\mathrm{y}} / A_{\mathrm{c}} f_{\mathrm{c}}^{\prime}$, than that of the T-SD400 specimen owing to the high yield stress of the material, referring to Lai et al. [13].

2.2. Test Setup and Loading. Figure 7(a) shows the layout of the test setup. As shown in Figures 7(a) and 7(b), the footing is fixed to the ground floor with eight bolts. It should be noted that to evaluate the ultimate strength of the connection part, a model with a fixed boundary condition has generally been used in previous studies $[14,15]$. The same approach was used in this study.

Lateral displacement was applied at the top of the RC pier by an actuator. The vertical axial load to the RC pier was not applied, such that pure flexural behavior could be 


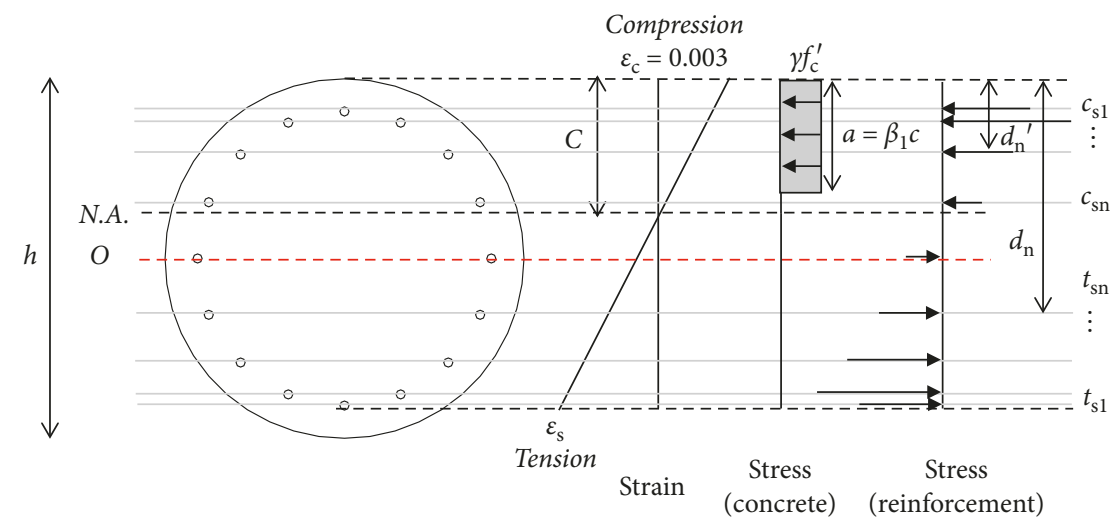

Figure 5: The strain and stress distributions of an RC section based on the strain compatibility method.

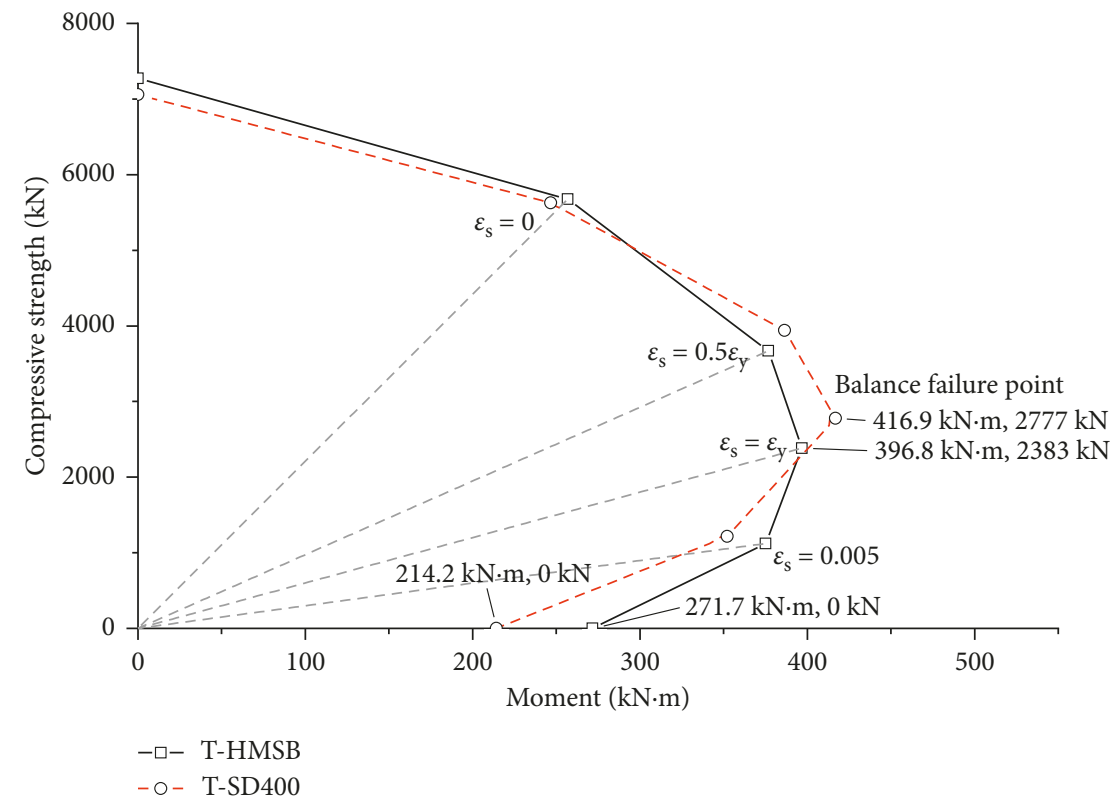

FIgURE 6: Theoretical $P$ - $M$ interaction curves for T-SD400 and T-HMSB specimens.

obtained. Because of the limited test resources, axial load testing was not conducted in this study. Instead, the effect of the axial force of the RC pier was examined by a series of verified FEAs, as discussed in Section 4.

Linear variable differential transformers were installed to measure the lateral displacement at the center of the loading point $(2,200 \mathrm{~mm}$ from the bottom of the pier). To measure the extreme strain in the reinforcing bar, strain gauges were attached at the outermost longitudinal reinforcing bars at the heights of 100,300 , and $500 \mathrm{~mm}$ from top of the footing, as shown in Figure 8. The displacement loading protocol shown in Figure 9 was applied to obtain the cyclic behavior and energy dissipation, as in Liao et al. [16].

\section{Test Results}

3.1. Damage Pattern and Base Moment-Drift Curve. Cyclic loading tests for the footing-to-circular RC pier connections were conducted. Figure 10 shows connection damage at a lateral displacement of $15 \mathrm{~mm}(0.68 \% \mathrm{drift})$ and the last cycle of the test. The test was completed when the lateral load decreased to $80 \%$ of the maximum lateral load. The drift ratios of the T-SD400 and T-HMSB in the last cycle were $5.48 \%$ and $10.09 \%$, respectively. The pushing (leftward in Figure 10) and pulling (rightward in Figure 10) directions were set as the positive direction and negative directions, respectively.

At $0.68 \%$ drift, similar flexural cracks were observed for both test specimens. Upon increasing the drift ratio, more flexural cracks developed. Then, the concrete at the connection part was crushed by excessive compression. Additionally, at the final stage, the reinforcing bars were buckled and ruptured in both directions in both specimens. The concrete damage level of T-SD400 was higher than that of the T-HMSB, even if the drift ratio of the last stage of T-HMSB (10.09\%) was much larger than that of T-SD400 (5.48\%), because HMSB has a higher yield and ultimate stress than ordinary reinforcing bars, and less compression 


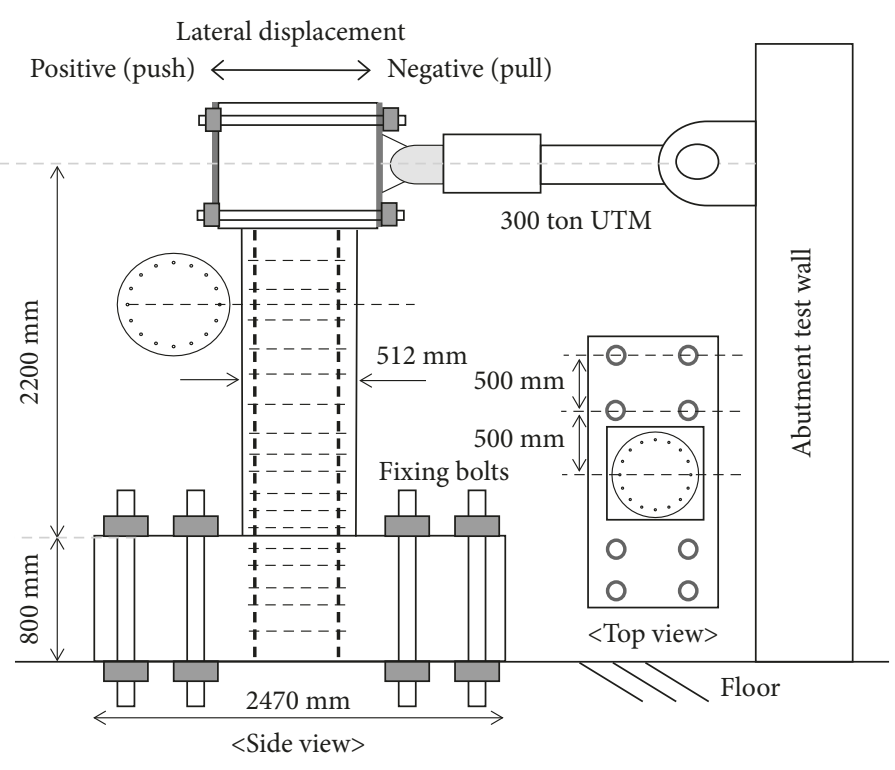

(a)

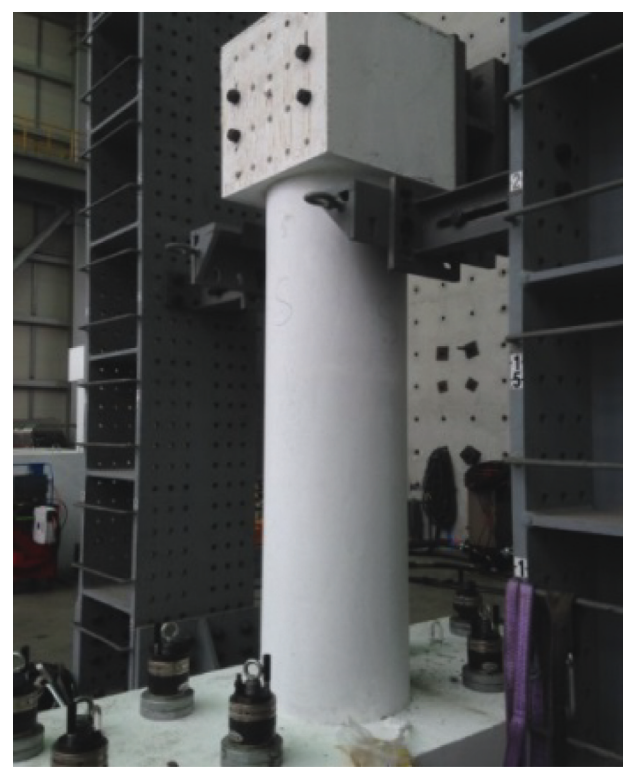

(b)

Figure 7: Test setup: (a) layout of loading and (b) the specimen on the frame.

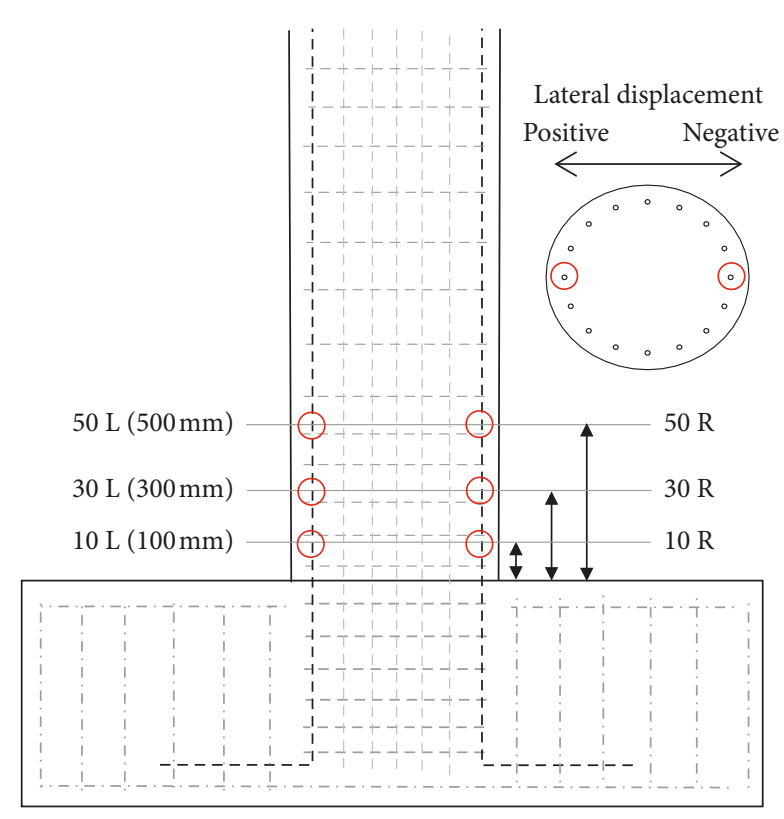

Figure 8: The location of the strain gauges.

developed in the concrete of T-HMSB. Moreover, the width of the flexural cracks at the failure of T-HMSB was longer than that of T-SD400, as shown in Figures 10(c) and 10(d). Based on Marefat et al. [17], this is probably due to the difference in the rebar surface (deformed circular reinforcing bars and plain rectangular reinforcing bars were used for T-SD400 and T-HMSB, respectively).

The base moment-drift ratio curves obtained from the test are shown in Figure 11. The base moment was calculated at the bottom of the pier. From Figure 11, it can be found that the ultimate base moment of T-HMSB was higher than that of T-SD400. The ultimate base moments from the test $\left(M_{\mathrm{u} \text {,test }}\right)$ were $261.06 \mathrm{kN} \cdot \mathrm{m}$ and $213.03 \mathrm{kN} \cdot \mathrm{m}$, respectively.

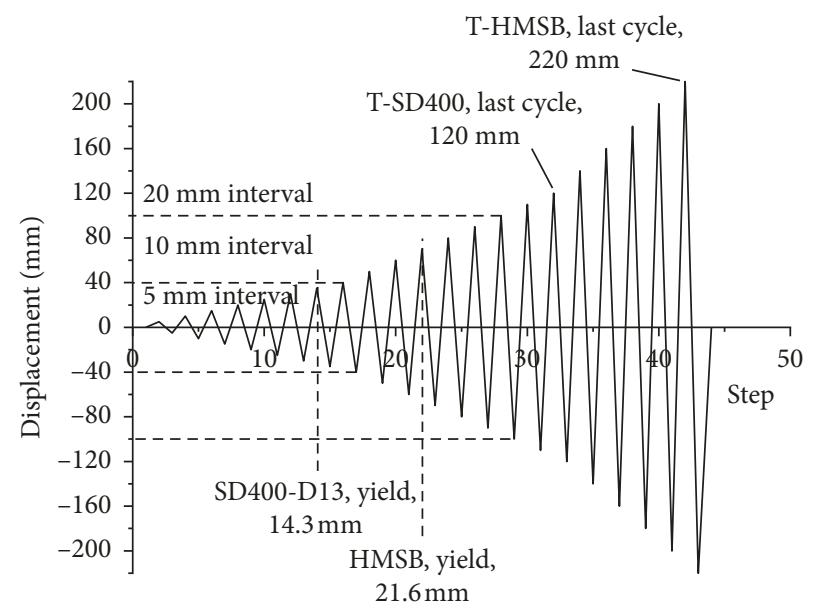

Figure 9: Cyclic lateral displacement control protocol.

Test results are summarized in Table 2. Additionally, the ultimate strengths of the test specimens are compared with theoretical predictions, as shown in Table 2. The theoretical ultimate strength of each specimen agrees well with the test results. The average discrepancy was $6.25 \%$.

3.2. Strain Analysis. Figure 12 shows the strain distributions in reinforcing bars with normalized moment-drift ratio curves for each test specimen. The base moment obtained from the test $\left(M_{\mathrm{u}, \text { test }}\right)$ was normalized to the theoretical ultimate strength $\left(M_{\mathrm{u}, \mathrm{scm}}\right)$. For the T-SD400 specimens, the strain data are almost linear up to $0.65 \%$ drift. However, the stiffness of the pier was dramatically reduced and the stain data were unstable for drift ratios beyond $0.65 \%$, as shown in Figure 12(a). Before the $0.65 \%$ drift, the flexural damages were not severe, and the reinforcing bars were well 


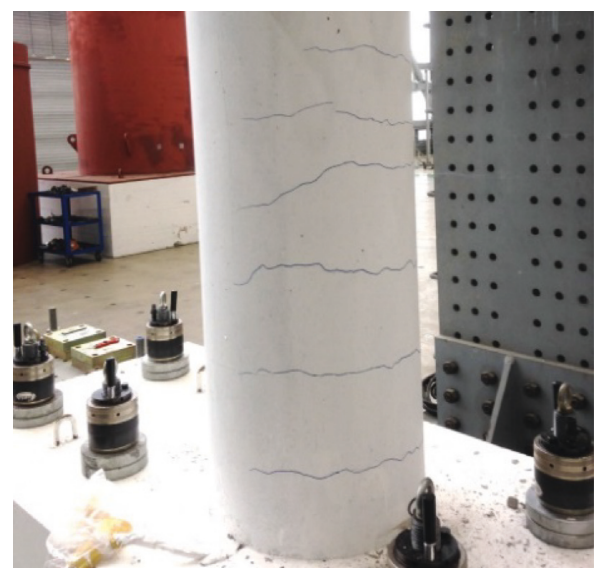

(a)

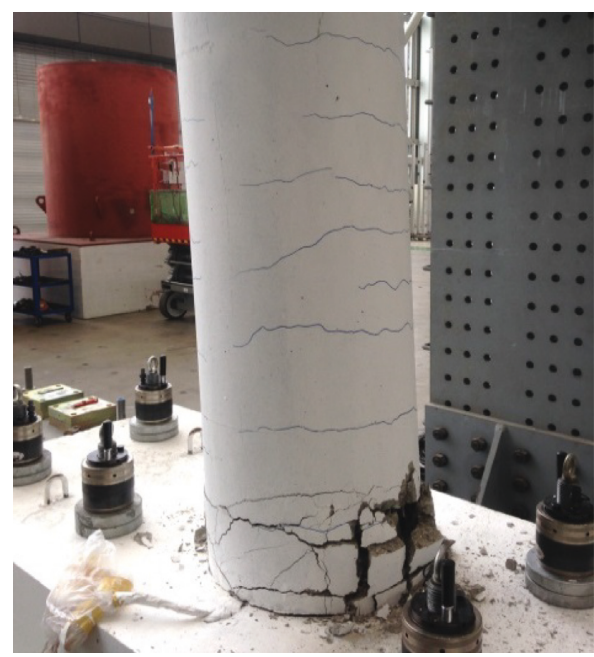

(c)

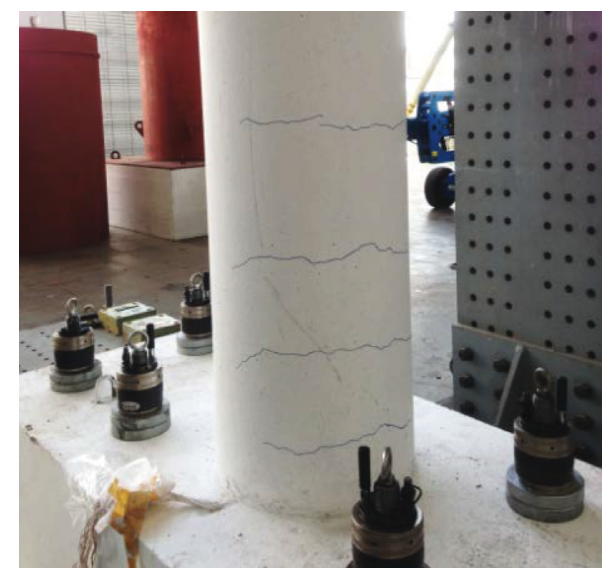

(b)

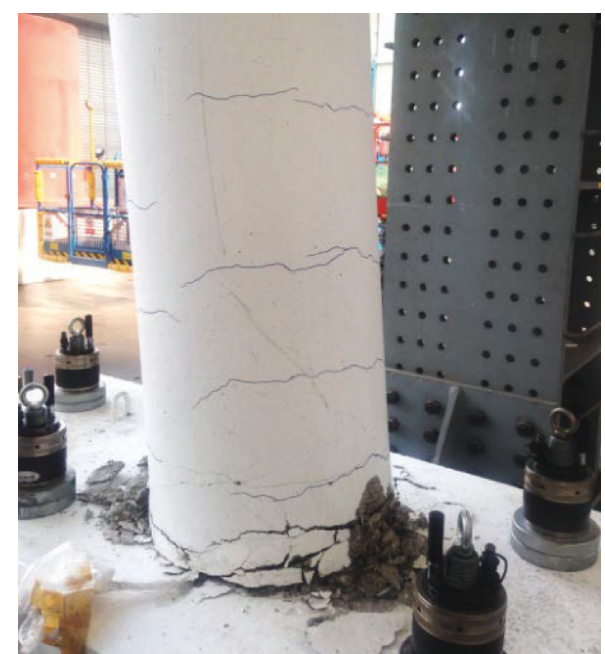

(d)

Figure 10: Connection damages: (a) T-SD400 at 0.67\% drift; (b) T-HMSB at $0.67 \%$ drift; (c) T-SD400 at 5.48\% drift (failure); and (d) THMSB at $10.09 \%$ drift (failure).

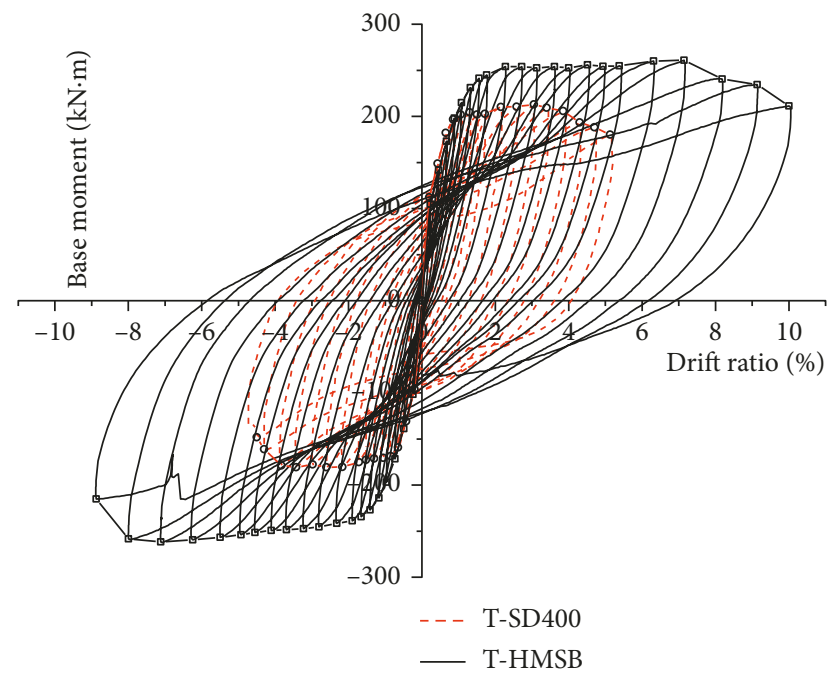

FIGURE 11: Base moment-drift ratio curves. embedded in the concrete. However, when the damage became severe, the crack opening increased and the stress concentration occurred at this point based on Hsu and Mo [18]. Furthermore, the pier experienced cyclic loading. Thus, uneven axial stresses in the longitudinal direction developed and the strain became unstable.

For the T-HMSB specimen, the strain data were almost linear up to a $2 \%$ drift ratio, as shown in Figure 12(b), after which nonlinear behavior was observed. However, the degree of nonlinearity was smaller than that for T-SD400. The maximum strains observed for T-SD400 and T-HMSB were 0.01856 and 0.02743 , respectively. The reinforcing bar rupture was observed for both test specimens. The strains at rupture were 0.164 and 0.307 for the SD400 bar and HMSB, respectively, in the standard tensile test, and these are much larger than the observed maximum strain of the bar in the test. However, this is reasonable, because the stress-strain relationship for the bar embedded in the concrete is different 
TABLE 2: Test results and comparison with the theoretical value.

\begin{tabular}{|c|c|c|c|c|c|c|}
\hline \multirow{2}{*}{ Specimen } & \multicolumn{2}{|c|}{$M_{\mathrm{u}, \text { test }}(\mathrm{kN} \cdot \mathrm{m})($ drift ratio) $(\%)$} & \multirow{2}{*}{$M_{\mathrm{u}, \mathrm{scm}}(\mathrm{kN} \cdot \mathrm{m})$} & \multicolumn{2}{|c|}{$M_{\mathrm{u}, \text { test }} / M_{\mathrm{u}, \mathrm{scm}}$} & \multirow{2}{*}{ Drift (\%) at $0.8 M_{\mathrm{u} \text {,test }}$} \\
\hline & Positive & Negative & & Positive & Negative & \\
\hline T-SD400 & $213.03(3.05)$ & $180.82(2.15)$ & 214.2 & 0.99 & 0.84 & 5.48 \\
\hline T-HMSB & $260.81(7.15)$ & $261.60(7.12)$ & 271.7 & 0.96 & 0.96 & 10.09 \\
\hline
\end{tabular}

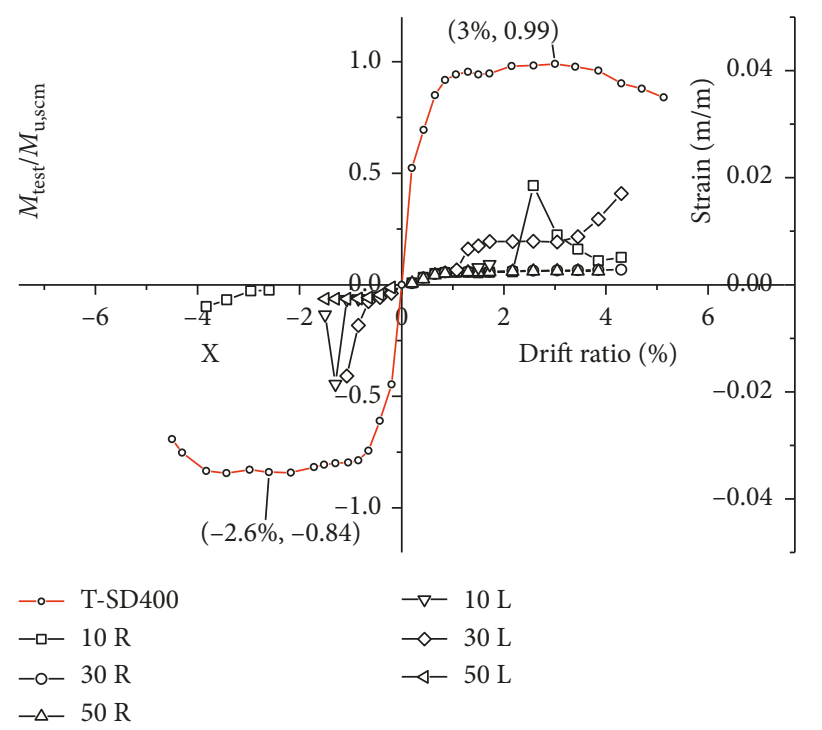

(a)

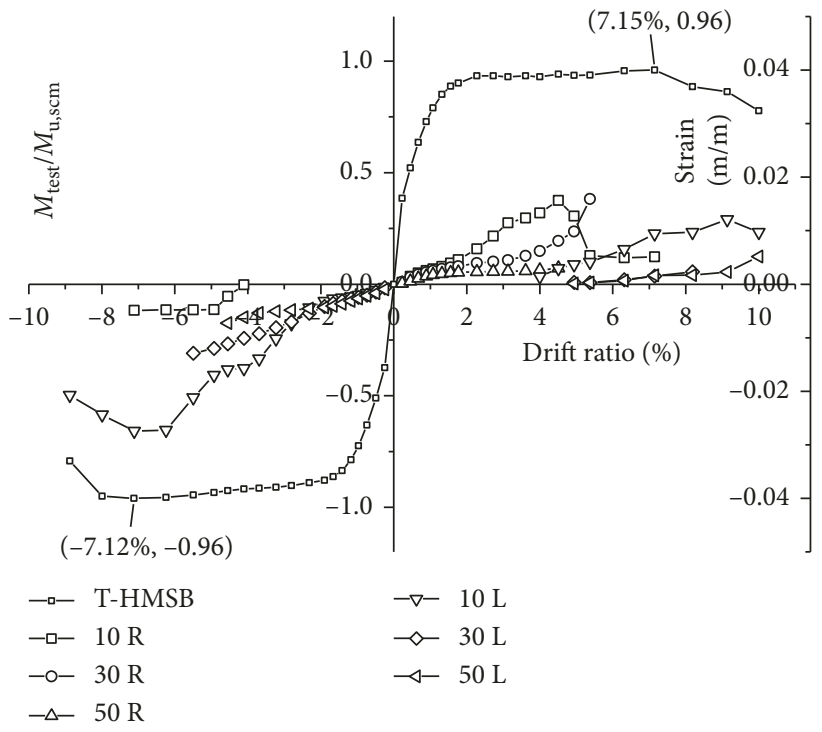

(b)

FIGURE 12: Strain distributions in reinforcing bars with the $M_{\mathrm{u}, \text { test }} / M_{\mathrm{u}, \mathrm{scm}}$ drift curve: (a) T-SD400 and (b) T-HMSB.

from that for the bare reinforcing bar, and the strain gauges are not attached to the rupture point.

The yield strains $\left(f_{\mathrm{y}} / E\right)$ of the SD400 bar and HMSB were 0.0022 and 0.0027 , respectively. These yield strains were achieved at drift ratios of $0.76 \%$ and $1 \%$, respectively. As a result, the yield moments can be approximately obtained as $189 \mathrm{kN} \cdot \mathrm{m}$ and $206 \mathrm{kN} \cdot \mathrm{m}$ for T-SD400 and T-HMSB, respectively.

3.3. Displacement Ductility and Energy Dissipation. Displacement ductility and energy dissipation are very important factors for evaluating seismic performance. They are evaluated from the test in this section. The displacement ductility $\left(\mu_{\mathrm{d}}\right)$ is computed as the ratio of the defined failure displacement to the idealized yield displacement suggested by Park [19], and $\mu_{\mathrm{d}}$ is given by

$$
\mu_{\mathrm{d}}=\frac{\Delta_{\mathrm{u}}}{\Delta_{\mathrm{yi}}},
$$

where $\Delta_{\mathrm{yi}}$ and $\Delta_{\mathrm{u}}$ represent the idealized yield displacement and ultimate displacement, respectively. In this study, $\Delta_{\mathrm{yi}}$ is defined as the yield displacement (or drift) of the equivalent elastoplastic system with reduced stiffness found as the secant stiffness at $75 \%$ of the ultimate normalized bending moment, $0.75 M_{\text {test }} / M_{\mathrm{u}, \mathrm{scm}} . \Delta_{\mathrm{u}}$ can be obtained from the displacement at $80 \%$ of the maximum normalized bending moment in the positive and negative directions, as discussed by Park [19]. Figures 13(a) and 13(b) show the displacement ductility for the T-SD400 and T-HMSB specimens, respectively. These results are summarized in Table 3.

The idealized yield displacement $\left(\Delta_{\mathrm{yi}}\right)$ of T-SD400 is $0.68 \%$, and the postpeak displacement $\left(\Delta_{\mathrm{u}}\right)$ of T-SD400 is $5.48 \%$ in the positive direction. In the negative direction, $\Delta_{\mathrm{yi}}$ is $0.62 \%$ and $\Delta_{\mathrm{u}}$ is $4.56 \%$. The calculated displacement ductility of T-SD400 is 8.56 and 7.35 in the positive and negative directions, respectively. For T-HMSB, $\Delta_{\mathrm{yi}}$ is $1.05 \%$ and $\Delta_{\mathrm{u}}$ is $10.09 \%$ in the positive direction, and $\Delta_{\mathrm{yi}}$ is $1.08 \%$ and $\Delta_{\mathrm{u}}$ is $9.01 \%$ in the negative direction. The calculated displacement ductility of T-HMSB is 9.61 and 8.34 in the positive and negative directions, respectively. As a result, the displacement ductility of T-HMSB is $12.35 \%$ and $13.53 \%$ higher than that of T-SD400 in the positive and negative directions, respectively.

Energy dissipation represents the energy absorbed by the structure during the cyclic loading excitation. According to Paulay et al. [20], the total dissipated energy $\left(E_{\text {hyst }}\right)$ is the sum of the energy dissipation, $\Delta w_{\mathrm{p}}$, over the cycles to failure and can be obtained as

$$
\begin{aligned}
& E_{\text {hyst }}=\sum \Delta w_{\mathrm{p}}, \\
& \Delta w_{\mathrm{p}}=\Delta_{x} \frac{\left(\sigma_{n}+\sigma_{n+1}\right)}{2},
\end{aligned}
$$

where $\Delta w_{\mathrm{p}}$ is the energy dissipation for one cycle, $\Delta_{x}$ is the variation in displacement, and $\sigma_{n}$ is the stress of each displacement. 


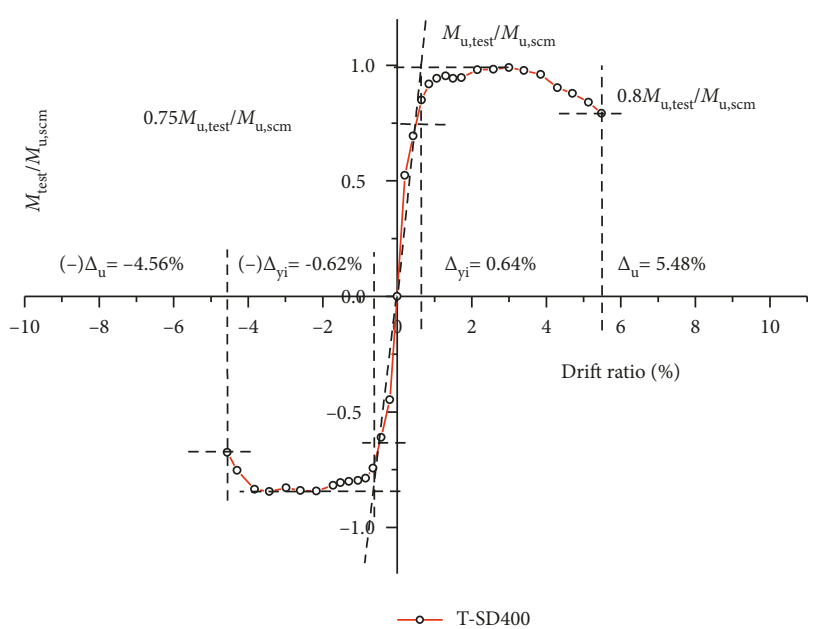

(a)

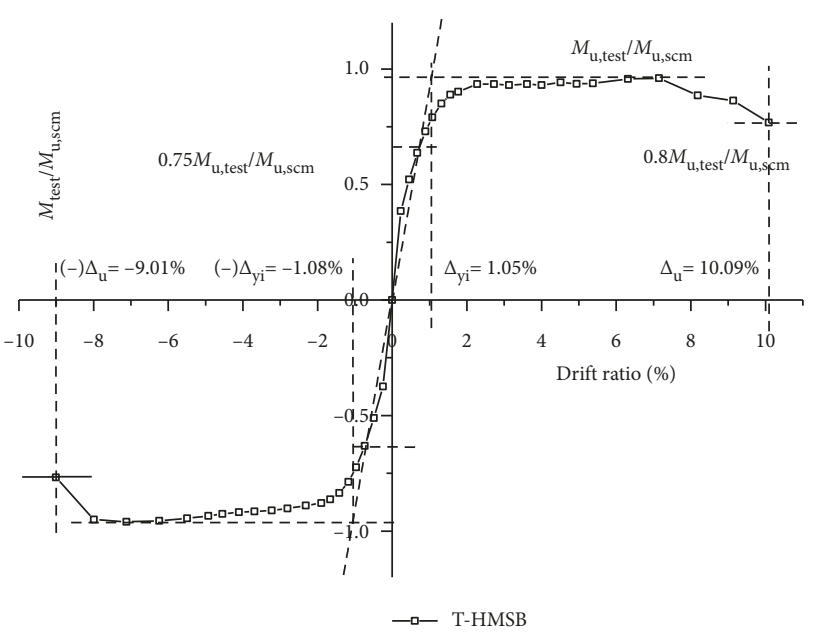

(b)

FIgURE 13: Displacement ductility calculation: (a) T-SD400 and (b) T-HMSB.

TABLE 3: Summary of displacement ductility calculation.

\begin{tabular}{cccccc}
\hline \multirow{2}{*}{ Specimen } & Direction & $\begin{array}{c}\text { Idealized yield displacement, } \Delta_{\mathrm{yi}} \\
(\%)\end{array}$ & $\begin{array}{c}\text { Failure displacement, } \Delta_{\mathrm{u}} \\
(\%)\end{array}$ & $\begin{array}{c}\text { Displacement ductility, } \\
\mu_{\mathrm{d}}\end{array}$ & Rate of increase (\%) \\
\hline \multirow{2}{*}{ T-SD400 } & Positive & 0.68 & 5.48 & 8.56 & - \\
& Negative & 0.62 & 4.56 & 7.35 & - \\
\multirow{2}{*}{ T-HMSB } & Positive & 1.05 & 10.09 & 9.61 & 12.35 \\
& Negative & 1.08 & 9.01 & 8.34 & 13.53 \\
\hline
\end{tabular}

The cumulative dissipated energy of each model was calculated, and the results are shown in Figure 14 and Table 4 . The cumulative dissipated energy of T-HMSB was $131 \%$ higher than that of T-SD400. The amount of cumulative dissipated energy was calculated by summing energy dissipation of all cycles until the completion of the test in each model. On the whole, T-HMSB showed higher displacement ductility and cumulative dissipated energy than did T-SD400. Thus, it can be concluded that the use of HMS as a reinforcing bar can improve the seismic performance of the footing-to-circular RC pier connection.

\section{Finite-Element Analysis}

4.1. Model Description and Verification. FEA was conducted by using ABAQUS [21] to investigate the effect of the axial load on the strength and ductility of the RC connection. Figure 15 shows the FEA model used in this study. The dimensions of the model were same as those of the test specimens. The FEA models with SD400-D13 reinforcing bars and HMSBs were named "F-SD400" and "F-HMSB," respectively.

The concrete of the FEA model was formed by using eight-node solid elements, as shown in Figure 15(a). The reinforcing bars were simulated using two-node truss elements, as shown in Figures 15(b) and 15(c). The EMBEDDED option in ABAQUS [21] was used to embed the reinforcements into the concrete. Thus, the interface between the concrete and the rebar is perfectly bonded. The STABILIZE option in ABAQUS [21] was used to ensure the

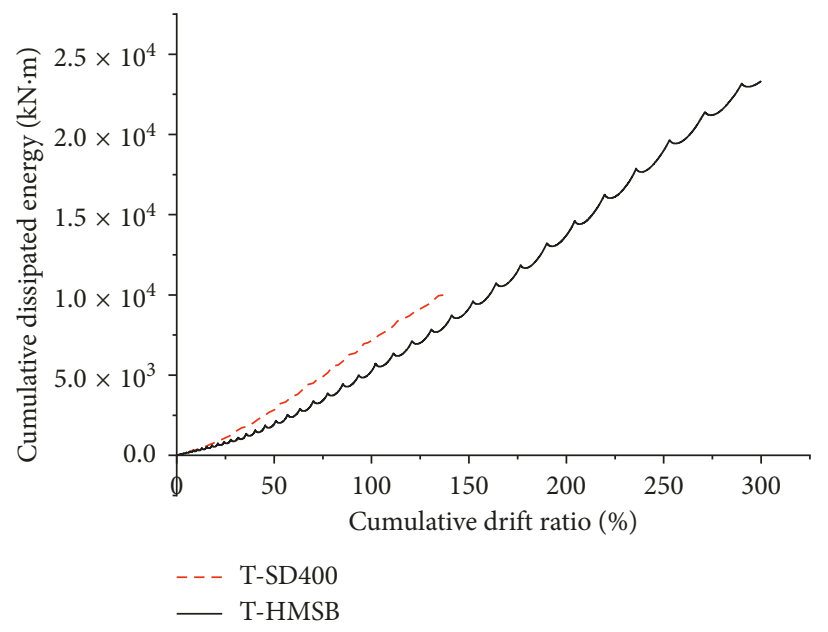

FIgURE 14: Cumulative dissipated energy for test specimens.

sufficient convergence of the analysis. It has been reported elsewhere $[22,23]$ that the STABILIZE option provides an automatic mechanism for stabilizing unstable quasi-static problems through the automatic addition of volumeproportional damping to the model.

For the efficiency of the analysis, a half model was used. The 1-2 plane cut in half of the model was symmetrically bounded, as shown in Figure 15(a). The fixed boundary condition was applied to the bottom of the model, and the bolting points are shown in Figure 15(a). The axial load was applied to the top of the pier by pressure, and the lateral 
TABLE 4: Summary of cumulative dissipated energy calculation results.

\begin{tabular}{lccc}
\hline Specimen & Cumulative drift ratio (\%) (up to $\left.0.8 M_{\mathrm{u}, \text { test }}\right)$ & Cumulative dissipated energy, $E_{\text {hyst }}(\mathrm{kN} \cdot \mathrm{m})$ & Rate of increase $(\%)$ \\
\hline T-SD400 & 138.97 & 10,112 & - \\
T-HMSB & 300.03 & 23,327 & 131 \\
\hline
\end{tabular}

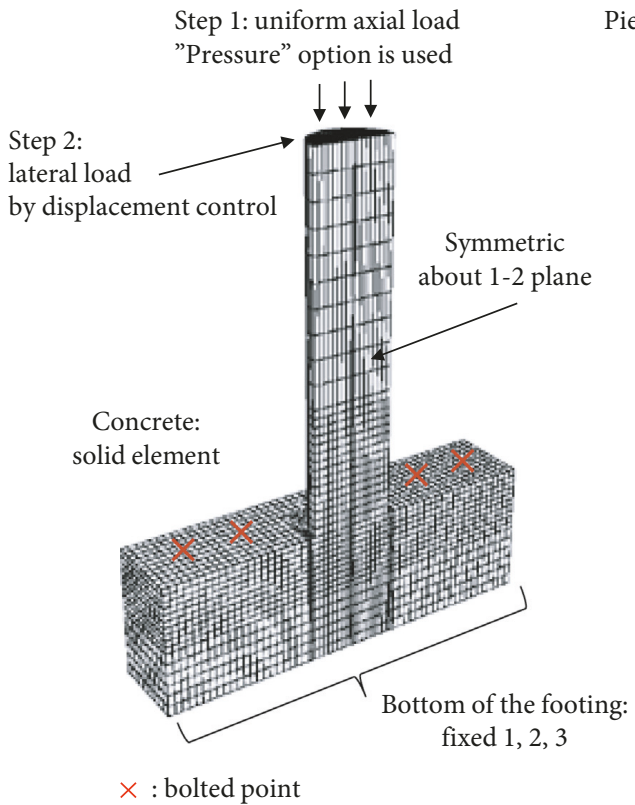

(a)
Pier reinforcements
truss element

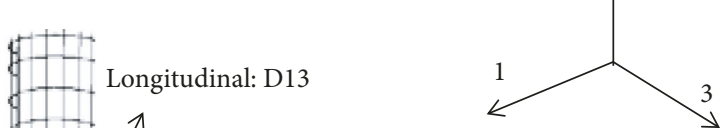

(b)

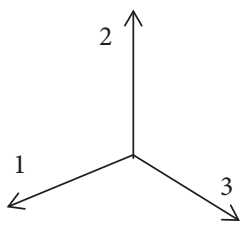

Footing reinforcements: truss element

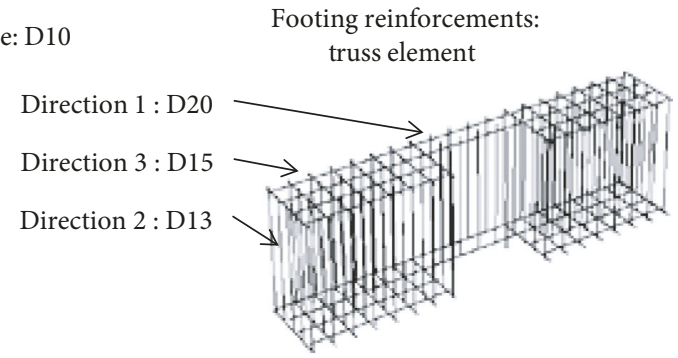

(c)

FIGURE 15: Typical finite-element model: (a) concrete elements, boundary condition, and loading; (b) reinforcing bars in the pier; and (c) reinforcing bars in the footing.

displacement was applied on the edge of the upper surface by using lateral displacements, as shown in Figure 15(a).

The uniaxial compressive stress-strain relationship proposed by Saenz [24] was used, where the elastic limit was set as $0.5 f_{\mathrm{c}}^{\prime}$. The strain corresponding to the maximum compressive strength $\left(\sqrt{f_{c}^{\prime}}\right)$ was assumed to be 0.003 . For the uniaxial tensile stress-strain curve, the results of Hsu and Mo [18] were applied, where the stress at the cracking of concrete $\left(f_{\mathrm{cr}}\right)$ was assumed to be $0.31 \sqrt{f_{\mathrm{c}}^{\prime}} \mathrm{MPa}$. In this study, the concrete damaged plasticity model proposed by Lee and Fenves [25] and available in ABAQUS [21] was used to simulate the 3D behavior of the stress. The concrete damaged plasticity model follows the nonassociated flow rule. Thus, the flow rule is needed to calculate the strain. The flow rule in the concrete damaged plasticity model is a function of the dilation angle, which is assumed to be $31^{\circ}$ as in elsewhere $[22,23,25]$. The other parameters in the concrete damage plasticity model were set as 0.1 for eccentricity (flow potential eccentricity), 1.16 for $f_{\mathrm{b} 0} / f_{\mathrm{c} 0}$ (ratio of initial equibiaxial compressive yield stress to initial uniaxial compressive yield stress), 0.67 for $\mathrm{K}$ (ratio of the second stress invariant), and 0 for viscosity (viscosity parameter).

The average stress-strain relationship of an embedded reinforcing bar differs from that of a bare reinforcing bar, because of cracking and the associated stress concentration near the cracking zone. To include these effects in the analysis model, the average stress-strain relationship of embedded reinforcing bars proposed by Hus and Mo [18] was applied. It is given by

$$
\begin{aligned}
& f_{\mathrm{r}}=E_{\mathrm{r}} \varepsilon_{\mathrm{r}} \text { when } f_{\mathrm{r}} \leq f_{\mathrm{yr}}^{\prime}, \\
& f_{\mathrm{r}}=(0.91-2 B) f_{\mathrm{yr}}+(0.02+0.25 B) E_{\mathrm{r}} \varepsilon_{\mathrm{r}} \text { when } f_{\mathrm{r}} \geq f_{\mathrm{yr}}^{\prime},
\end{aligned}
$$

where $f_{\mathrm{r}}$ and $\varepsilon_{\mathrm{r}}$ are the stress and strain in the reinforcing bar, respectively. $E_{\mathrm{r}}$ is Young's modulus of the reinforcing bar, and $f_{\mathrm{yr}}^{\prime}$ is the reduced yield stress of the embedded reinforcing bars and it is lower than the yield stress of the bare reinforcing bars. $f_{\mathrm{yr}}^{\prime}$ can be obtained as

$$
\begin{aligned}
f_{\mathrm{yr}}^{\prime} & =(0.93-2 B) f_{\mathrm{yr}}, \\
B & =\frac{1}{\rho}\left(\frac{f_{\mathrm{cr}}}{f_{\mathrm{yr}}}\right)^{1.5},
\end{aligned}
$$

where $f_{\mathrm{yr}}$ is the yielding stress of the reinforcement and $\rho$ is the reinforcement ratio. To simulate the 3D stress behavior of the reinforcing bar, the von Mises yield criterion with isotropic hardening was used. Finally, the uniaxial stress-strain relationships for the concrete and the reinforcing bar used in FEA model are plotted as Figures 16(a) and 16(b), respectively.

GTN (Gurson-Tvergaard-Needleman) model is suitable to simulate the ductile failure of the steel member such as 


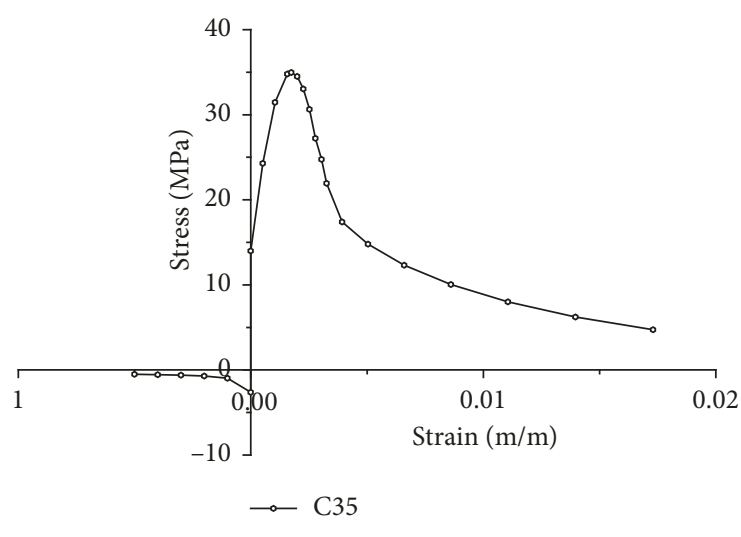

(a)

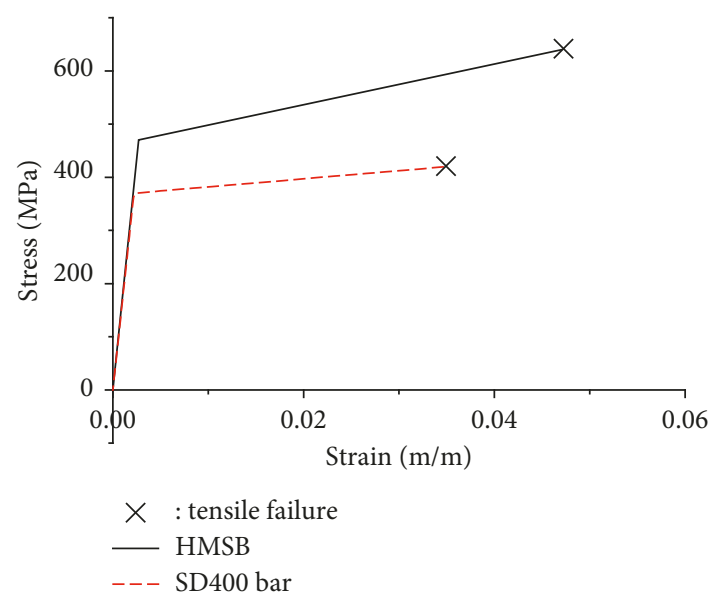

(b)

FIgURE 16: The stress-strain curve used in FEA: (a) concrete and (b) embedded reinforcing bar.

reinforcing bar failure [26], and it can be applicable to determine the strains corresponding to the rupture of the reinforcing bars. However, GTN model parameters are not known for HMSBs. As an alternative, the strains corresponding to the rupture of the reinforcing bars are obtained from an inverse analysis by matching the deterioration behavior of FEA results with the tests. The rupture strains are set as 0.035 and 0.047 for F-SD400 and F-HMSB, respectively. A mesh convergence study was conducted to ensure the convergence of the FEA model. Considering the discrepancy and analysis time, the mesh size of $50 \mathrm{~mm}$ was adopted in the analysis model.

The FEA was conducted for the test specimen for verification. Figures 17 (a) and 17(b) compare the FEA results with the test results. Figures $17(\mathrm{a})$ and $17(\mathrm{~b})$ show that the FEA results agree well with the test results. The stiffnesses at early drift are very similar in both cases. The ultimate strengths obtained from the FEA are very close to those from the test. Additionally, the drift at failure obtained from the FEA is reasonable in comparison to the test. Thus, the verification results indicate that the developed FE model is appropriate for accurately evaluating the behavior of footing-to-circular RC connections.

The stress distributions and crack patterns of the analysis model at final stage are shown in Figures 18 and 19 for F-SD400 and F-HMSB, respectively. The final drift ratios of F-SD400 and F-HMSB are $4.46 \%$ and $7.91 \%$, respectively. In Figure 18(a), the reinforcements are yielded and the maximum value of the stress reaches the ultimate stress in tension side. The concrete stresses are shown in Figure 18(b), and it can be found that the part near the footing-to-RC pier connection becomes a plastic hinge. It is assumed that the cracks are developed in the perpendicular direction of the maximum principal plastic tensile strain for the concrete damaged plasticity model. Thus, crack patterns can be visualized as Figure 18(c). In Figure 18(c), in tension side, flexural cracks are observed in the wide area including plastic hinge zone. In Figure 19(a), the reinforcements in tension side are yielded more widely than those of F-SD400. Concrete stress of the F-HMSB is lower than that of the F-SD400 in the final stage, as shown in Figure 19(b). This is because the compressive strain exceeds the strain at the compressive strength of the concrete, and the softening behavior is occurred. In Figure 19(c), severe cracks are observed in tension side and most of the concrete are damaged due to the large drift ratio.

4.2. Parametric Study. A parameter analysis was performed to evaluate the effect of the axial load. The pier is generally subjected to an axial load, and the moment capacity and failure mechanism change depending on the magnitude of the axial load. $P$ - $M$ interaction curves are constructed for the test specimens, as shown in Figure 6. From these curves, four different axial load ratios, $r=P / P_{0}, 0,0.1,0.15$, and 0.3 , were selected for the parameter study, and the corresponding axial forces and moment capacity are summarized in Table 5, in which $P_{0}$ is the squash load of the pier, calculated from $0.85 f_{\mathrm{c}}^{\prime} A_{\mathrm{c}}+f_{\mathrm{y}} A_{\mathrm{s}}$, and $P$ is the applied axial load.

For the four axial loads shown in Table 5, the FEA was conducted for both F-SD400 and F-HMSB models. The analysis results are shown in Figure 20. The base moment obtained from the FEA was calculated, including the $P-\Delta$ effect. The effects of the axial load for the F-SD400 and F-HMSB models are similar to each other. With increasing axial forces, the strength deterioration after ultimate strength becomes large. This is because the concrete crushing in the compression zone becomes significant with increasing axial load, and the failure mechanism changes from ductile reinforcing bar failure to brittle concrete failure.

Based on the analysis results shown in Figure 20, the displacement ductility was evaluated for each analysis case, and the results are shown in Figure 21. Additionally, the ultimate strength comparisons with the theoretical values are summarized in Table 6. From Table 6 and Figure 21, it can be found that the ultimate moment capacity obtained 


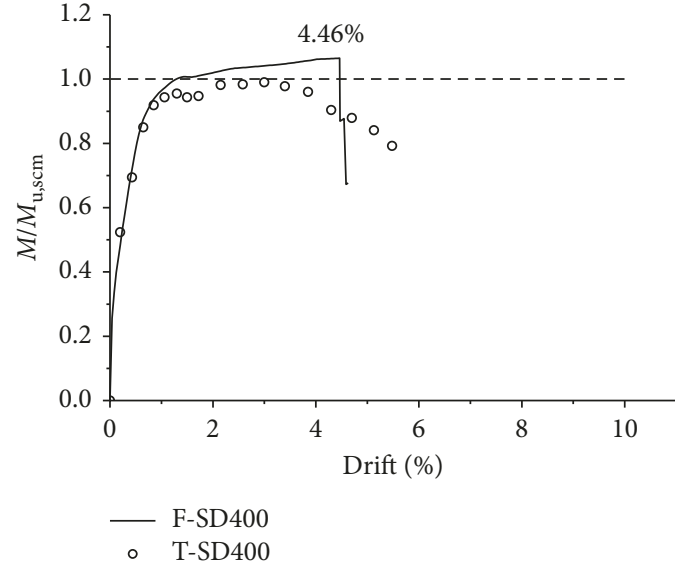

(a)

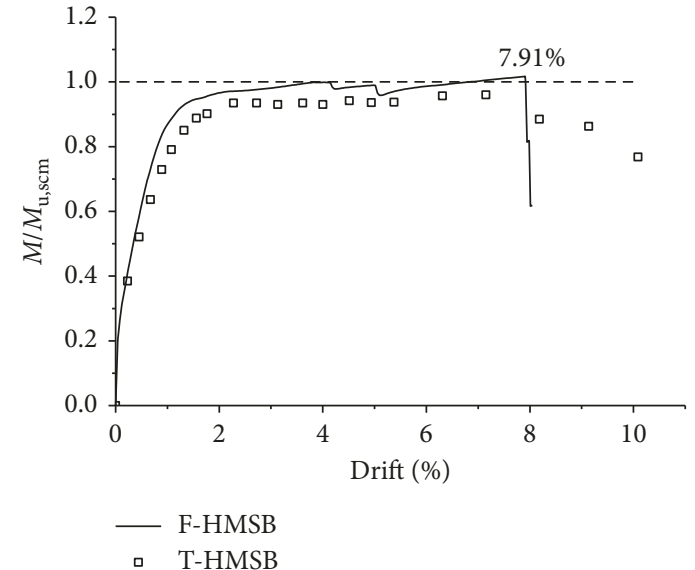

(b)

Figure 17: Verification results: (a) F-SD400 vs. T-SD400 and (b) F-HMSB vs. T-HMSB.

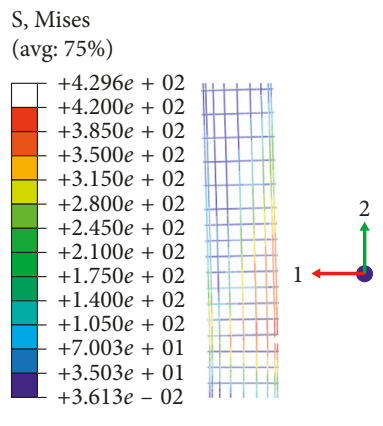

(a)
S, S22

(avg: $75 \%$ )

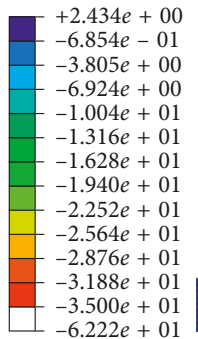

$-3.500 e+01$
$-6.222 e+01$

(b)
PE, Max, principal (avg: $75 \%$ )

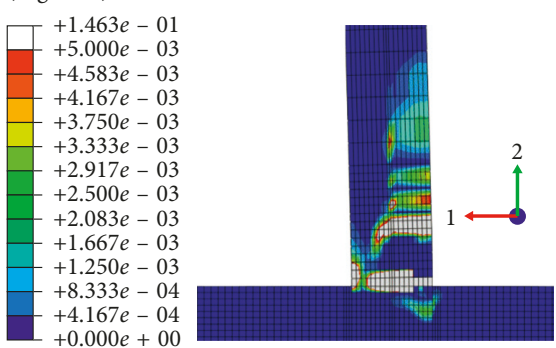

(c)

FIGURE 18: F-SD400 at the final stage (4.46\%): (a) reinforcement stress distributions; (b) concrete stress distributions; and (c) concrete cracks.

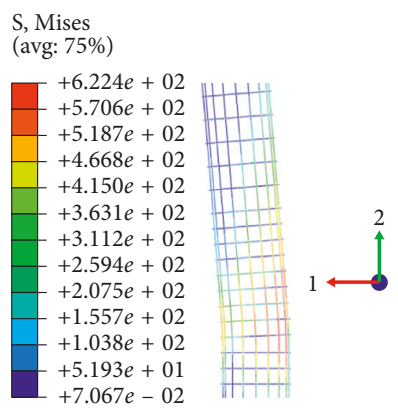

(a)
S, S22 (avg: 75\%)

$+2.223 e+00$
$-8.786 e-01$
$-3.981 e+00$
$-7.082 e+00$
$-1.018 e+01$
$-1.329 e+01$
$-1.639 e+01$
$-1.949 e+01$
$-2.259 e+01$
$-2.569 e+01$
$-2.880 e+01$
$-3.190 e+01$
$-3.500 e+01$
$-3.624 e+01$

(b)

PE, Max, principal (avg: $75 \%$ )

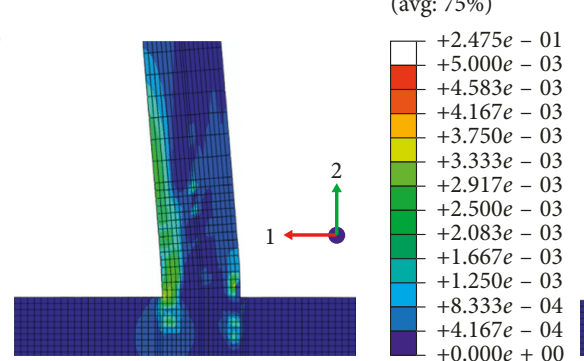

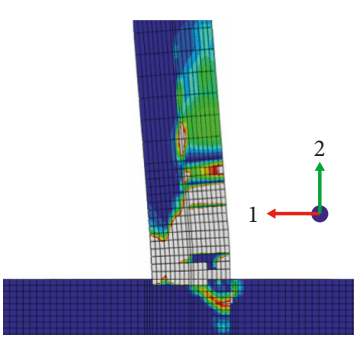

(c)

Figure 19: F-HMSB at the final stage (7.91\%): (a) reinforcement stress distributions; (b) concrete stress distributions; and (c) concrete cracks.

from the FEA agrees well with the theoretical values when the axial load is not large. The discrepancy between the FEA and theory increases with increasing axial load. The displacement ductility of F-HMSB is larger than that in the F-SD400 model. The displacement ductility reaches its maximum in the range from $0.1 P_{0}$ to $0.15 P_{0}$.

\section{Conclusions}

In this study, HMSBs were used as reinforcing bars to improve the seismic performance of the footing-to-circular RC pier connection. Circular RC pier connection specimens with HMSBs and ordinary reinforcing bars were constructed 
TABLE 5: Axial load ratios and corresponding theoretical moment capacity.

\begin{tabular}{lcccc}
\hline Parameter & \multicolumn{2}{c}{ F-SD400 } & F-HMSB \\
Axial load ratio, $r=P / P_{0}$ & Axial load, $P(\mathrm{kN})$ & $\begin{array}{c}\text { Ultimate moment, } \\
M_{\mathrm{u}, \mathrm{scm}}(\mathrm{kN} \cdot \mathrm{m})\end{array}$ & Axial load, $P(\mathrm{kN})$ & Ultimate moment, $M_{\mathrm{u}, \mathrm{scm}}(\mathrm{kN} \cdot \mathrm{m})$ \\
\hline 0 & 0 & 214.21 & 0 & 271.7 \\
0.1 & 706 & 300.00 & 727 & 341.24 \\
0.15 & 1,059 & 336.77 & 1,091 & 373.58 \\
0.30 & 2,118 & 389.54 & 2,182 & 393.52 \\
\hline
\end{tabular}

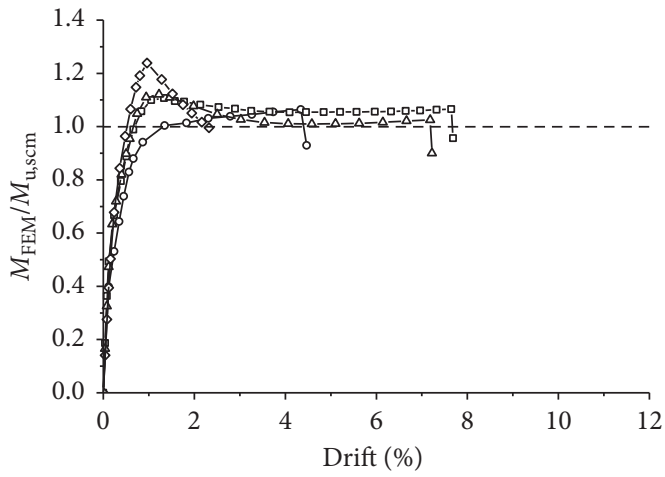

$$
\begin{aligned}
& \text { F-SD400 } \\
& \multimap 0 P_{0} \\
& \multimap-0.1 P_{0} \\
& \rightarrow-0.15 P_{0} \\
& \multimap 0.3 P_{0}
\end{aligned}
$$

(a)

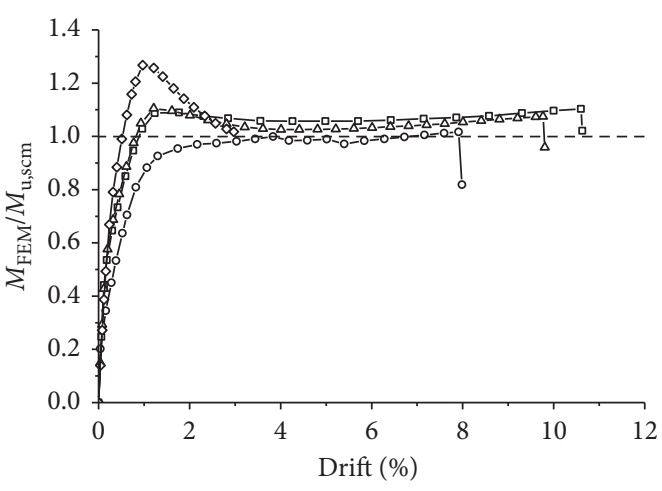

$$
\begin{aligned}
& \text { F-HMSB } \\
& \multimap 0 P_{0} \\
& \multimap-0.1 P_{0} \\
& -\triangle 0.15 P_{0} \\
& \multimap 0.3 P_{0}
\end{aligned}
$$

(b)

FIGURe 20: The results of parameter study: (a) F-SD400 and (b) F-HMSB.

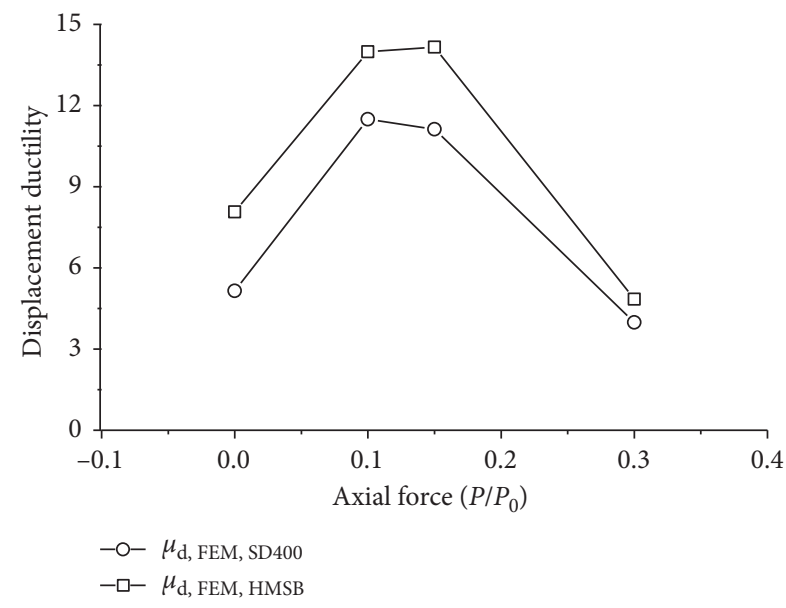

FIGURE 21: Displacement ductility of FEM analysis models.

and tested to investigate the pure flexural behavior of the connection. Furthermore, FEA was conducted to examine the effect of the axial load on the proposed connection. From the test and analysis results, the following conclusions are drawn:

(1) From the flexural test with zero axial load, it was found that the test specimen with HMSBs (T-HMSB) has $22 \%, 13 \%$, and $131 \%$ higher ultimate strength, displacement ductility, and dissipated energy, respectively. The use of HMSB could provide better seismic performance than can the conventional reinforcing bar.

(2) From the test, it was found that the flexural crack width of T-HMSB is larger than that of the specimen with ordinary reinforcing bars (T-SD400), because the HMSB used in this study had a plain surface and rectangular shape. For a more accurate comparison, a connection with circular deformed HMSB should be tested. However, even for the HMSB with a plain surface and rectangular shape, the connection with HMSBs showed better seismic performance.

(3) The effect of the axial load on the proposed RC connection was investigated by a series of FEAs. The results showed that the displacement ductility of the 
TABLE 6: Summary of the parameter analysis results.

\begin{tabular}{|c|c|c|c|c|c|}
\hline Model & Axial load ratio, $r=P / P_{0}$ & $M_{\mathrm{u}, \text { test }} / M_{\mathrm{u}, \mathrm{scm}}$ & $\begin{array}{c}\text { Idealized yield displacement, } \\
\Delta_{\mathrm{yi}, \mathrm{FEM}}(\%)\end{array}$ & $\begin{array}{c}\text { Failure displacement, } \\
\Delta_{\mathrm{u}, \mathrm{FEM}}(\%)\end{array}$ & $\begin{array}{c}\text { Displacement ductility, } \\
\mu_{\mathrm{d}, \mathrm{FEM}}\end{array}$ \\
\hline \multirow{4}{*}{ F-SD400 } & 0 & 1.06 & 0.87 & 4.48 & 5.15 \\
\hline & 0.1 & 1.11 & 0.67 & 7.7 & 11.49 \\
\hline & 0.15 & 1.13 & 0.65 & 7.23 & 11.12 \\
\hline & 0.3 & 1.24 & 0.6 & 2.39 & 3.98 \\
\hline \multirow{4}{*}{ F-HMSB } & 0 & 1.02 & 0.99 & 7.99 & 8.07 \\
\hline & 0.1 & 1.10 & 0.76 & 10.63 & 13.99 \\
\hline & 0.15 & 1.10 & 0.69 & 9.77 & 14.16 \\
\hline & 0.3 & 1.27 & 0.63 & 3.05 & 4.84 \\
\hline
\end{tabular}

analysis model with HMSBs was higher than that with conventional reinforcing bars for all considered axial load ratios. The displacement ductility reached its maximum in the range from $0.1 P_{0}$ to $0.15 P_{0}$ for both connections.

\section{Data Availability}

The data used to support the findings of this study are available from the corresponding author upon request.

\section{Conflicts of Interest}

The authors declare that they have no conflicts of interest.

\section{Acknowledgments}

This study was supported by the Research Grant from Kangwon National University.

\section{References}

[1] Y.-C. Ou, M.-S. Tsai, K.-C. Chang, and G. C. Lee, "Cyclic behavior of precast segmental concrete bridge columns with high performance or conventional steel reinforcing bars as energy dissipation bars," Earthquake Engineering and Structural Dynamics, vol. 39, no. 11, pp. 1181-1198, 2010.

[2] X. Xiao, F. Guan, and S. Yan, "Use of ultra-high-strength bars for seismic performance of rectangular high-strength concrete frame columns," Magazine of Concrete Research, vol. 60, no. 4, pp. 253-259, 2008.

[3] J. Su, R. P. Dhakal, J. Wang, and W. Wang, "Seismic performance of RC bridge piers reinforced with varying yield strength steel," Earthquakes and Structures, vol. 12, no. 2, pp. 201-211, 2017.

[4] A. Budek, M. Priestley, and C. Lee, "Seismic design of columns with high-strength wire and strand as spiral reinforcement," ACI Structural Journal, vol. 99, no. 5, pp. 660-670, 2002.

[5] M. Deng and Y. Zhang, "Seismic performance of high-ductile fiber-reinforced concrete short columns," Advances in Civil Engineering, vol. 2018, Article ID 3542496, 11 pages, 2018.

[6] A. Lepage, H. Tavallali, S. Pujol, and J. M. Rautenberg, "Highperformance steel bars and fibers as concrete reinforcement for seismic-resistant frames," Advances in Civil Engineering, vol. 2012, Article ID 450981, 13 pages, 2012.

[7] T. Sasaki, K. Watanabe, K. Nohara, Y. Ono, and N. Kondo, "Physical and mechanical properties of high manganese nonmagnetic steel and its application to various products for commercial use," Transactions of the Iron and Steel Institute of Japan, vol. 22, no. 12, pp. 1010-1020, 1982.

[8] AASHTO, AASHTO LRFD Bridge Design Specification, AASHTO, Washington, DC, USA, 6th edition, 2012.

[9] U. Poudyal, "Development length criteria for plain and Ransome bars," M.S. thesis," University of Saskatchewan, Saskatoon, Canada, http://hdl.handle.net/10388/8454, 2018.

[10] Eurocode2, Design of Concrete Structures, Part 1.1: General Rules and Rules for Building, European Committee for Standardization, Brussels, Belgium, 2004.

[11] Eurocode4, Design of Composite Steel and Concrete Structures, Part 1.1: General Rules and Rules for Building, European Committee for Standardization, Brussels, Belgium, 2004.

[12] AISC, Design Examples V14.2, American Institute of Steel Construction, Chicago, IL, USA, 2011.

[13] Z. Lai, A. H. Varma, and L. G. Griffis, "Analysis and design of noncompact and slender CFT beam-columns," Journal of Structural Engineering, vol. 142, no. 1, article 04015097, 2016.

[14] K. S. Park, J. Moon, S. S. Lee, and C. W. Roeder, "Embedded steel column-to-foundation connection for a modular structural system," Engineering Structures, vol. 110, pp. 244257, 2016.

[15] J. Moon, D. E. Lehman, C. W. Roeder, and H. E. Lee, "Evaluation of embedded concrete-filled tube (CFT) columnto-foundation connections," Engineering Structures, vol. 56, pp. 22-35, 2013.

[16] W.-C. Liao, W. Perceka, and M. Wang, "Experimental study of cyclic behavior of high-strength reinforced concrete columns with different transverse reinforcement detailing configurations," Engineering Structures, vol. 153, pp. 290-301, 2017.

[17] M. S. Marefat, S. M. H. Shirazi, R. Rostamshirazi, and M. Khanmohammadi, "Cyclic response of concrete beams reinforced by plain bars," Journal of Earthquake Engineering, vol. 13, no. 4, pp. 463-481, 2009.

[18] T. T. C. Hsu and Y.-L. Mo, Unified Theory of Concrete Structures, John Wiley \& Sons, Hoboken, NJ, USA, 2nd edition, 2010.

[19] R. Park, "Evaluation of ductility of structures and structural assemblages from laboratory testing," Bulletin of the New Zealand National Society for Earthquake Engineering, vol. 22, no. 3, pp. 155-166, 1989.

[20] T. Paulay, M. Priestley, and A. Synge, "Ductility in earthquake resisting squat shear walls," ACI Structural Journal, vol. 79, no. 4, pp. 257-269, 1982.

[21] ABAQUS, ABAQUS Analysis User's Manual Version 6.12, Dassault Systemes Simulia, Providence, RI, USA, 2012.

[22] J. Moon, D. E. Lehman, C. W. Roeder, H.-E. Lee, and T.-H. Lee, "Analytical evaluation of reinforced concrete pier and cast-in-steel-shell pile connection behavior considering 
steel-concrete interface," Advances in Materials Science and Engineering, vol. 2016, Article ID 4159619, 14 pages, 2016.

[23] J. Moon, C. W. Roeder, D. E. Lehman, and H.-E. Lee, "Analytical modeling of bending of circular concrete-filled steel tubes," Engineering Structures, vol. 42, pp. 349-361, 2012.

[24] L. P. Saenz, "Discussion of "equation for the stress-strain curve of concrete" by P. Desayi and S. Krishnan," ACI Structural Journal, vol. 61, no. 9, pp. 1229-1235, 1964.

[25] J. Lee and G. L. Fenves, "Plastic-damage model for cyclic loading of concrete structures," Journal of Engineering $\mathrm{Me}$ chanics, vol. 124, no. 8, pp. 892-900, 1998.

[26] C. Amadio, C. Bedon, M. Fasan, and M. R. Pecce, "Refined numerical modelling for the structural assessment of steelconcrete composite beam-to-column joints under seismic loads," Engineering Structures, vol. 138, pp. 394-409, 2017. 


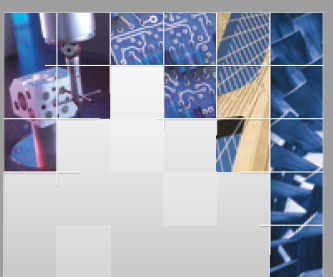

\section{Enfincering}
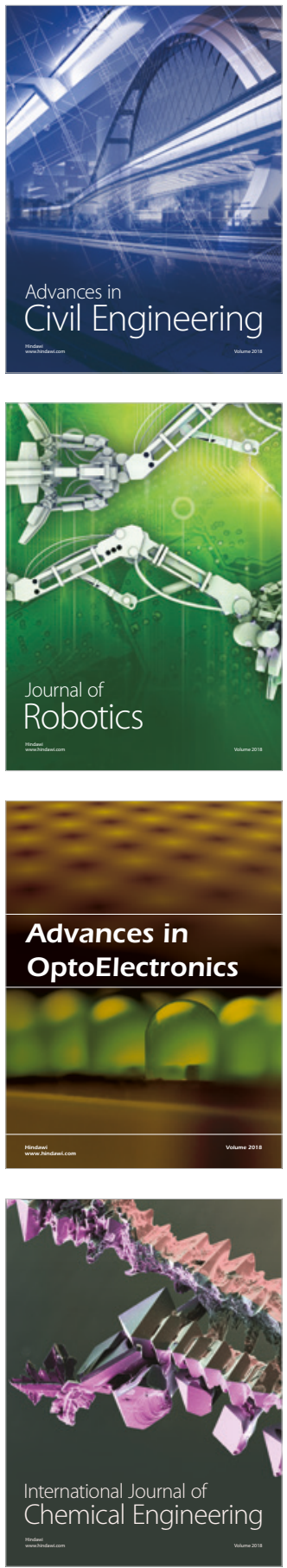

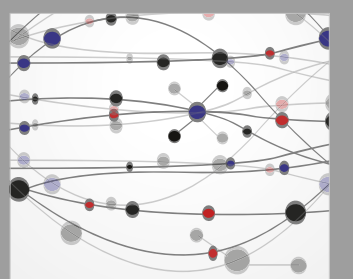

\section{Rotating \\ Machinery}

The Scientific World Journal

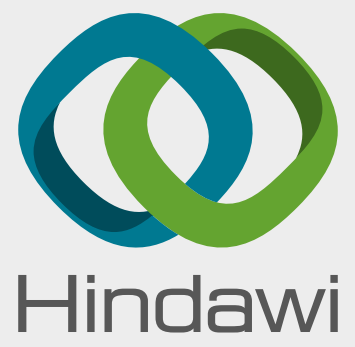

Submit your manuscripts at

www.hindawi.com
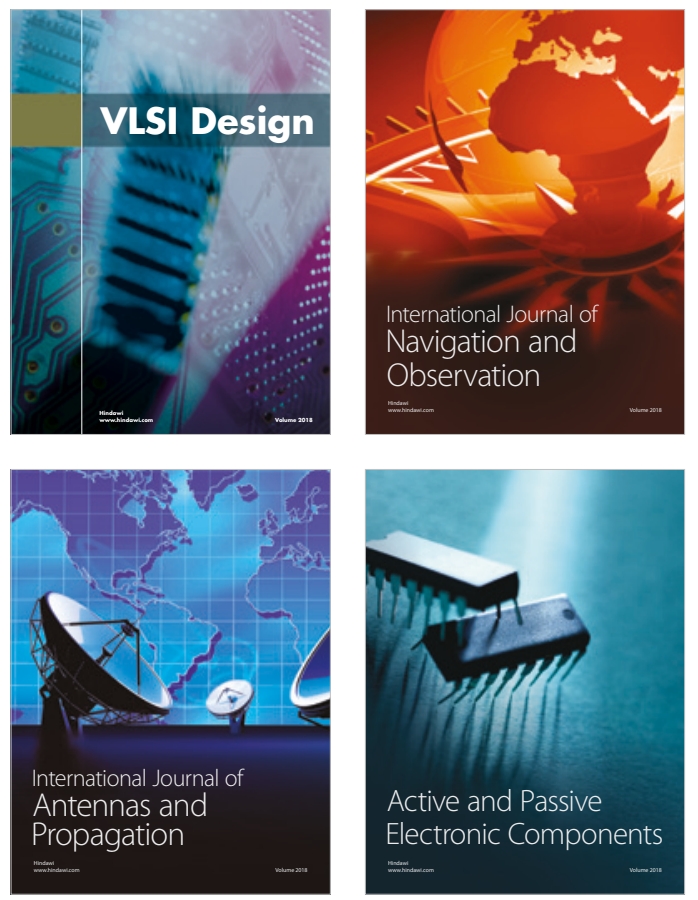
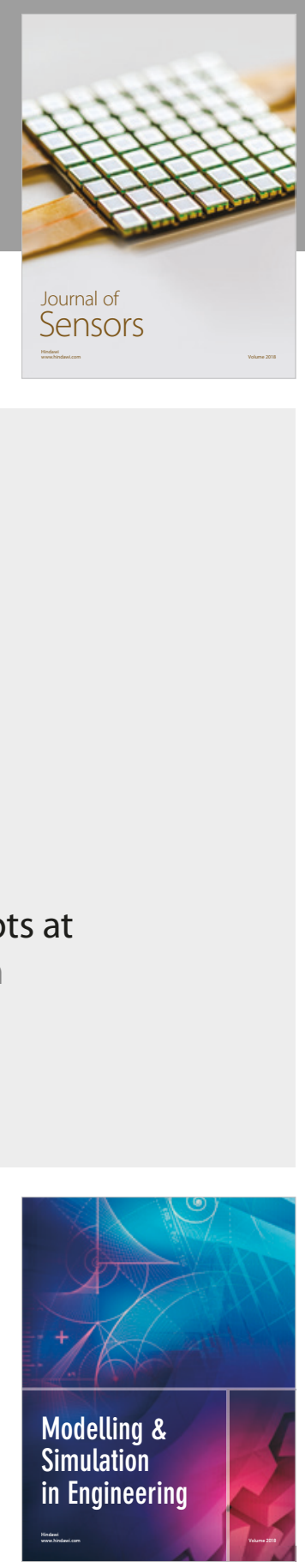

\section{Advances \\ Multimedia}
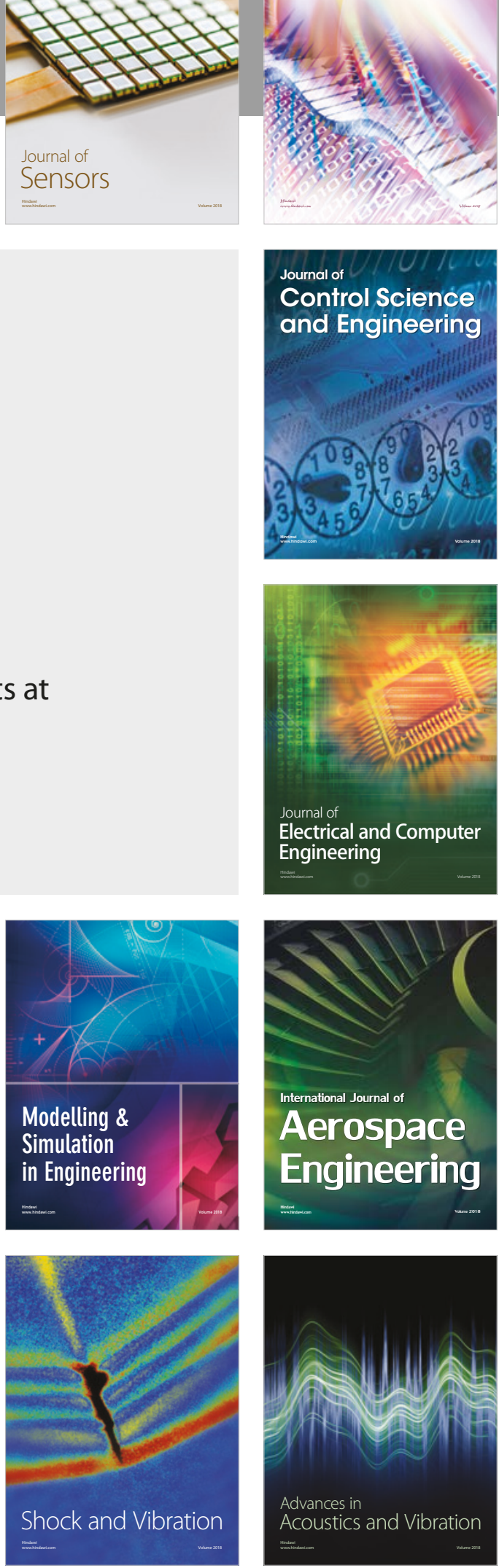